\title{
Familial Dysbetalipoproteinemia Associated with Apolipoprotein E3-Leiden in an Extended Multigeneration Pedigree
}

\author{
Peter de Knijff,* Arn M. J. M. van den Maagdenberg, ${ }^{*}$ Anton F. H. Stalenhoef, Jan A. Gevers Leuven,* \\ Pierre N. M. Demacker," Lambertus P. Kuyt," Rune R. Frants, ${ }^{*}$ and Louis M. Havekes* \\ *Gaubius Laboratory, Institute of Ageing and Vascular Research, Netherlands Organization for Applied Scientific Research, Leiden; \\ ${ }^{\ddagger}$ Department of Human Genetics, Leiden University, Leiden; ${ }^{8}$ Department of General Internal Medicine, University Hospital, Nijmegen, \\ Nijmegen;and "Institute of Human Genetics, Free University, Amsterdam, The Netherlands
}

\begin{abstract}
By the careful screening of familial dysbetalipoproteinemic (FD) patients, five probands showing heterozygosity for the APOE*3-Leiden allele were found. Genealogical studies revealed that these probands share common ancestry in the 17th century. In a group of 128 family members, spanning three generations, 37 additional heterozygous APOE*3-Leiden gene carriers were detected. Although with a variable degree of severity, all carriers exhibited characteristics of FD such as (a) elevated levels of cholesterol in the very low density lipoprotein (VLDL) and intermediate density lipoprotein (IDL) fractions, (b) elevated ratios of cholesterol levels in these density fractions over total plasma levels of triglycerides, and (c) strongly increased plasma levels of apolipoprotein $\mathbf{E}$ (apoE). Multiple linear regression analysis revealed that most of the variability in expression of FD in APOE*3-Leiden allele carriers can be explained by age. Body mass index showed a less significant influence on the expression of FD. Gender had no effect on the expression in $\mathrm{E}^{\star} 3$-Leiden allele carriers, nor did it influence the age of onset of FD. In the group of APOE*3-Leiden allele carriers, we found that the $E^{\star} 2$ allele enhances the expression of $F D$, whereas the $E^{\star} \mathbf{4}$ allele had the opposite effect. Isoelectric focusing of plasma and of isolated VLDL, IDL, and high density lipoprotein density fractions showed that in $E^{\star} 3$-Leiden allele carriers the apoE3-Leiden variant largely predominates over its normal apoE counterpart, especially in the VLDL and IDL density fractions. We conclude that in APOE*3-Leiden allele carriers FD is dominantly inherited with a high rate of penetrance, i.e., the presence of normally functioning apoE molecules in the plasma does not prevent the age-related expression of this disease. (J. Clin. Invest. 1991. 88:643-655.) Key words: body mass index • dominant expression • family studies • high penetrance • type III hyperlipoproteinemia
\end{abstract}

\section{Introduction}

Familial dysbetalipoproteinemia (FD) ${ }^{1}$ is a genetic disorder of the lipoprotein metabolism predisposing to premature coro-

This study was presented in part at the 55th Meeting of the European Atherosclerosis Society, Brugge, Belgium, 17-19 May 1990.

Address reprint requests to Dr. Havekes, Gaubius Laboratory, IVVO-TNO, P.O. Box 430, 2300 AK Leiden, The Netherlands.

Received for publication 21 December 1990 and in revised form 5 April 1991.

1. Abbreviations used in this paper: BMI, body mass index; FD, familial dysbetalipoproteinemia; PCR, polymerase chain reaction.

J. Clin. Invest.

(C) The American Society for Clinical Investigation, Inc. $0021-9738 / 91 / 08 / 0643 / 13 \$ 2.00$

Volume 88, August 1991, 643-655 nary and/or peripheral vascular disease (1). Patients with FD are characterized by elevated plasma cholesterol and triglycerides levels owing to the presence of $\beta$-migrating chylomicron and very low density lipoprotein (VLDL) remnants enriched in cholesterol and apolipoprotein E (apoE) (2-4). As a consequence, the ratio of VLDL-cholesterol to plasma triglyceride levels is elevated. Approximately $50 \%$ of the patients show lipid deposits like palmar streaks and tuberous xanthomas (1).

ApoE, one of the major protein constituents of chylomicron and VLDL remnants, plays a central role in the receptormediated endocytosis of these particles functioning as a highaffinity ligand for hepatic lipoprotein receptors $(5,6)$. The primary metabolic defect in FD patients is due to mutant forms of apoE on chylomicron and VLDL remnants leading to an impaired clearance of these remnant particles by the liver $(1,7,8)$.

By isoelectric focusing, three common genetic variants of apoE, designated E2, E3, and E4 according to their mobility upon isoelectric focusing, can be recognized. They each differ in isoelectric point by one charge unit, apoE4 being the most basic and apoE2 the most acidic isoform. These isoforms are encoded for by three codominant alleles, $E^{*} 2, E^{*} 3$, and $E^{*} 4$, at a single APOE gene locus on chromosome 19 (9). The common apoE2 is derived from the wild-type apoE3, by a cysteine for arginine substitution at amino acid residue 158 [designated as apoE2(Arg158 $\rightarrow$ Cys)], whereas apoE4 is derived from apoE3 by an arginine for cysteine substitution at residue 112 [apoE4(Cys1 12 $\rightarrow$ Arg)].

The vast majority of FD patients are homozygous for the apoE2(Arg158 $\rightarrow$ Cys) variant (1). In vitro experiments showed that this variant exhibits only $1 \%$ of the receptor binding capacity of normal apoE3 (10). Since homozygosity for the apoE2(Arg158 $\rightarrow$ Cys) variant is required in order to develop $\mathrm{FD}$, this variant is associated with a recessive mode of inheritance of FD. In Caucasian populations homozygosity for apoE2(Arg158 $\rightarrow$ Cys) occurs with a frequency of $1 \%$, whereas the frequency of FD is about 1:2,500 (1). Thus, only a small percentage of these E2E2 individuals will develop FD (1). This indicates that, in general FD is a multifactorial disease, i.e., additional factors, either genetic or environmental, are required for its manifestation $(11,12)$.

Expression of FD has also been observed in individuals heterozygous for the rare apoE variants, such as apoE3(Cys1 $12 \rightarrow$ Arg; Arg142 $\rightarrow$ Cys) $(13,14)$, apoE2(Lys146 $\rightarrow$ Gln) (15-17), and apoE1-Harrisburg(Lys146 $\rightarrow$ Glu), which focuses one charge unit more acidic than E2 $(18,19)$. Family studies have confirmed that heterozygosity for these rare variants is associated with the development of FD despite the presence of a "normal" APOE allele, indicating that with these variants FD is dominantly inherited with a high degree of penetrance.

Previously, we have reported on a patient with FD exhibiting heterozygosity for a rare apoE variant focusing at the E3 
position, lacking cysteine residues, and designated as apoE3Leiden $(20,21)$. By analyzing first-degree relatives, we were able to show that in this family the apoE3-Leiden variant was strongly associated with the occurrence of FD (21). Recently, DNA and protein sequencing analyses revealed that the APOE*3-Leiden allele was identical to the APOE*4(Cys112 $\rightarrow$ Arg) allele, but included an in-frame repeat of 21 nucleotides (coding for seven amino acids) in exon 4 . Since it was impossible to define exactly the duplication unit because of identical sequences at bp positions 3768-3772 and 3789-3793 of the normal apoE sequence (numbering according to Paik et al. [22]), the insertion leads to a tandem repeat of codons 120-126 or 121-127 $(23,24)$. The seven-amino acids insert introduces one extra negatively charged glutamyl residue when compared with the common apoE4(Cys112 $\rightarrow$ Arg) variant and thus leads to a focusing on the apoE3 position.

In this article we describe four additional probands showing FD in association with heterozygosity for apoE3-Leiden. Genealogical studies revealed that the five probands share common ancestry. A detailed characterization of the effect of heterozygosity for the APOE*3-Leiden allele on lipoprotein levels has been performed by studying family members of the five E3Leiden pedigrees. All APOE*3-Leiden allele carriers showed clinical signs of FD, although with a variable degree of severity. Because of the relatively large number of APOE*3-Leiden allele carriers available $(n=42)$, we were able to estimate the effects of age, body mass index (BMI), and gender on the expression of FD in apoE3-Leiden carriers by statistical analysis. We also determined the influence of the accompanying "normal" APOE allele on the expression of FD in these E3-Leiden subjects.

\section{Methods}

Subjects. The initial proband (CV) is a Caucasian male who was previously described as a FD patient with heterozygosity for the apoE3Leiden variant (20). Subsequently, his first-degree relatives members were studied and five more gene carriers were found, all exhibiting FD (21). Later, four other, apparently unrelated probands with FD and heterozygosity for apoE3-Leiden have been found in lipid clinics in Nijmegen and Leiden.

Genealogical studies. Information presented to us by the five probands enabled us to perform genealogical studies. This was done by checking the parish records from the 18th century and the civil registration, population, and census records from the 19th and 20th centuries in a region southeast of The Hague. We learned that in this region there is no high degree of consanguinity.

Collection of blood samples. From the five probands and 123 relatives, EDTA blood samples were collected. Individuals were allowed to consume a low calorie (fat free) breakfast. Plasma was separated from the cells by centrifugation at $500 \mathrm{~g}$ for $10 \mathrm{~min}$ at room temperature and used for lipid and lipoprotein analysis; the cells were used to isolate genomic DNA.

Lipid and lipoprotein analysis. For the isolation of VLDL ( $d$ $<1.006 \mathrm{~g} / \mathrm{ml}$ ), $2 \mathrm{ml}$ of plasma was overlaid with a $2.5-\mathrm{ml}$ solution of $\mathrm{NaCl}(d=1.006 \mathrm{~g} / \mathrm{ml})$ in a $5-\mathrm{ml}$ tube fitting the $40 \mathrm{Ti}$ swing-out rotor (Beckman Instruments, Geneva, Switzerland). After centrifugation at $90,000 \mathrm{~g}$ for $16 \mathrm{~h}$ at $4^{\circ} \mathrm{C}$, VLDL was aspirated from the top. High density lipoprotein (HDL) was determined in the infranatant after precipitation of intermediate density lipoprotein (IDL) and low density lipoprotein (LDL) (25). For the isolation of VLDL + IDL $(d<1.019$ $\mathrm{g} / \mathrm{ml}), 2 \mathrm{ml}$ of plasma was brought to a background density of 1.019 $\mathrm{g} / \mathrm{ml}$ with $\mathrm{KBr}$ and overlaid with a $3.5-\mathrm{ml}$ solution of $\mathrm{NaCl}(d=1.019$ $\mathrm{g} / \mathrm{ml}$ ) in a 10.4-ml centrifuge tube fitting the $50 \mathrm{Ti}$ fixed-angle rotor
(Beckman Instruments). After centrifugation at $106,000 \mathrm{~g}$ for $16 \mathrm{~h}$ at $4^{\circ} \mathrm{C}$, VLDL + IDL were aspirated from the top.

Plasma cholesterol and cholesterol in the VLDL $(d<1.006 \mathrm{~g} / \mathrm{ml})$, VLDL + IDL $(d<1.019 \mathrm{~g} / \mathrm{ml})$, and HDL-cholesterol were measured using the CHOD-PAP kit (no. 236691, Boehringer, Mannheim, FRG). Plasma and lipoprotein triglycerides were measured using the GPOPAP kit (no. 701904, Boehringer, Mannheim). IDL-cholesterol was calculated as the difference between VLDL-cholesterol $(d<1.006 \mathrm{~g})$ $\mathrm{ml})$ and VLDL + IDL-cholesterol $(d<1.019 \mathrm{~g} / \mathrm{ml})$. LDL-cholesterol $(1.019<d<1.063 \mathrm{~g} / \mathrm{ml})$ was calculated using the formula: LDL-chol $=$ plasma chol $-($ VLDL-chol + IDL-chol + HDL-chol).

Agarose electrophoresis was performed as described by Demacker et al. (26).

ApoE quantification, phenotyping, and genotyping. ApoE concentrations in plasma were measured by ELISA as described by Bury et al. (27). In short, affinity-purified polyclonal goat anti-human apoE antibodies, raised in our institution as described before (28), were used both for coating and for preparing the antibody-peroxidase conjugate. The pool plasmas of healthy individuals, used as internal standards, were calibrated with a standard curve constructed with purified human apoE as primary standard. Mean intra- and interassay coefficients of variance were $4.3 \%$ and $8.2 \%$, respectively.

The apoE phenotype was determined by isoelectric focusing of delipidated plasma samples before and after cysteamine treatment followed by immunoblotting as described (28). For apoE phenotyping in the different lipoprotein fractions, VLDL, IDL, and HDL fractions were isolated by density-gradient ultracentrifugation of freshly prepared plasma by the method of Redgrave et al. (29) followed by extensive dialysis of the fractions against phosphate-buffered saline (PBS).

For genotyping, genomic DNA was isolated from leukocytes by standard methods (30). The 5' part of exon 4 of the APOE gene was amplified by the polymerase chain reaction (PCR) using the primers 402 (nucleotides 3555-3574, coding strand) and 401 (nucleotides 3932-3913, noncoding strand) (22) (Fig. 1) giving a fragment of $378 \mathrm{bp}$ (or $399 \mathrm{bp}$ in the case of the APOE*3-Leiden allele). This fragment encodes the amino acid residues 61-174 of the mature protein (see Fig. 1 and reference 23).

After PCR, $5-\mu$ l aliquots were separated on a $2 \%$ agarose gel by electrophoresis, and the gel was stained with ethidium bromide and photographed. Thereafter the DNA was transferred to a membrane (Biotrace, Gelman Sciences, Inc., Ann Arbor, MI) and hybridized with a $\left[\gamma-{ }^{32}\right.$ P]ATP-labeled synthetic allele-specific oligonucleotide probe directed against the junction region of the APOE*3-Leiden gene duplication (23).

For allele-specific restriction endonuclease genotyping as described first by Hixson and Vernier (31), $15 \mu$ of PCR product was digested with $7.5 \mathrm{U} \mathrm{Hhal} \mathrm{at} 37^{\circ} \mathrm{C}$ for $16 \mathrm{~h}$ according to recommendations of the supplier (Pharmacia, Uppsala, Sweden). Thereafter, the digested material was separated on a $10 \%$ neutral polyacrylamide gel for $3 \mathrm{~h}$ at 10 $\mathrm{V} / \mathrm{cm}$, stained with ethidium bromide, and photographed.

Statistics. All statistical calculations were performed with the use of the commercially available statistical package, Number Cruncher Statistical Systems, developed by Dr. J. L. Hinze (Kaysville, UT). In order to avoid the possibility of ascertainment bias, the five probands were omitted from all calculations. Since the studied population involves family members (not randomly selected individuals), and most of the measured parameters showed non-Gaussian distributions, differences in these parameters between groups were calculated using either the nonparametric analysis of variance (ANOVA) test of Kruskal-Wallis (in the case of more than two groups) or the Mann-Whitney test (in the case of two groups). Differences in gender distribution between two groups were evaluated with $\chi^{2}$ analysis. Spearman's rank correlation was calculated to test for a linear correlation between age and BMI. Multiple regression analysis to determine the independent effects of age, BMI, and gender was performed on logarithmic transformed data in order to avoid non-Gaussian distribution of the dependent variables. $P$ values lower than 0.05 were considered as indicative of significant differences. 


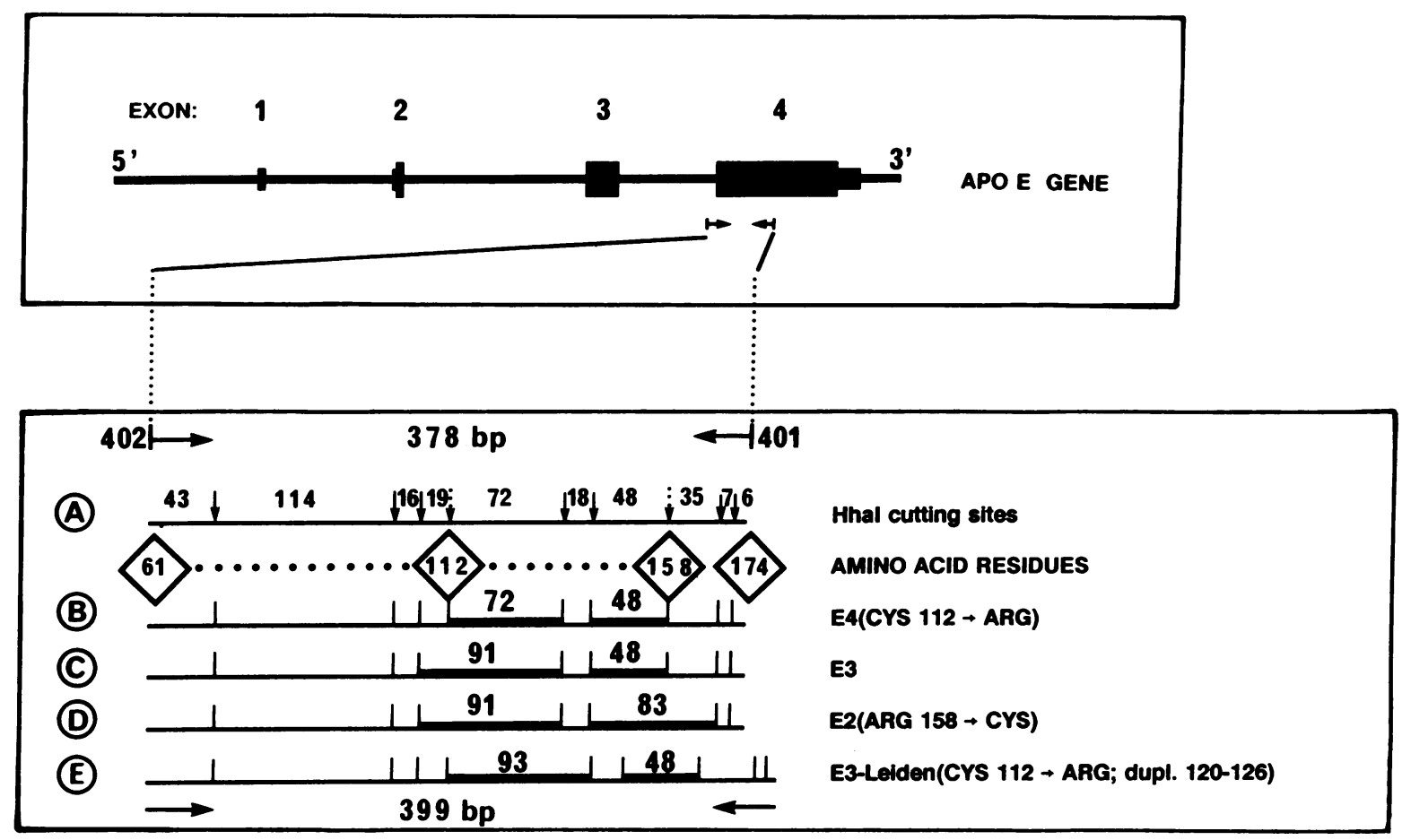

Figure 1. Top: Schematic representation of the APOE gene. Narrow boxes indicate the nontranslated part and broad boxes indicate the translated parts of the exons. Bottom: Enlarged 5' part of exon 4 of the APOE gene showing the position of the two amplification primers $402 / 401(\rightarrow$ and $\leftarrow)$. Lane $A$ shows the 378-bp PCR product of normal apoE using these two amplification primers. The constant $(\downarrow)$ and variable (v) Hhal restriction endonuclease cutting sites are indicated. The positions of the amino acid residues $61,112,158$, and 174 are also indicated $(\diamond)$. Lane $B$ represents the 378-bp PCR product of apoE4(Cys $112 \rightarrow$ Arg) with the 72-bp Hhal restriction fragment length unique for this allele. Lane $C$ represents the 378-bp PCR product of apoE3 with the combination of the 91- and 48-bp Hhal restriction fragment lengths unique for this allele. Lane $D$ represents the 378-bp PCR product of apoE2(Arg $158 \rightarrow$ Cys) with its unique combination of a 91- and 83-bp Hhal restriction fragment lengths. Lane $E$ shows the 399-bp PCR product of apoE3-Leiden. Since the apoE3-Leiden mutation adds 21 bp to the 72-bp HhaI restriction fragment length normally found for the APOE*4(Cys $112 \rightarrow \mathrm{Arg}$ ) allele, the resulting 93-bp fragment is a unique feature of this apoE variant.

\section{Results}

Probands. Besides the original proband (CV), four additional, apparently unrelated, probands (GW, $\mathrm{AB}, \mathrm{JB}$, and JE) showing heterozygosity for the APOE*3-Leiden allele have currently been identified among Dutch FD patients. One of these (AB) was previously reported as apoE3-Nijmegen (32). Table I represents the results of the lipid analysis and clinical characteristics of the five probands at their first visit to a lipid clinic. Three apoE3-Leiden probands show the signs and symptoms typical for FD. The remaining two probands had the clinical signs only. ApoE isoelectric focusing patterns of the five probands are shown in Fig. 2. All probands showed only partial modification with cysteamine, indicating heterozygosity for apoE3-Leiden (21). As shown in Fig. 2, four probands (GW, AB, JB, and JE) have the apoE3E3-Leiden phenotype whereas the original proband CV exhibits the apoE2E3-Leiden phenotype. The presence of the APOE*3-Leiden allele in these subjects was further proved by genotyping using agarose electrophoresis of amplified DNA that corresponds to the 5' part of exon 4 of the APOE gene. All five probands exhibited a 399-bp band in addition to the common 378-bp band indicating the presence of the 21-bp insert reported for apoE3-Leiden (Fig. 3 A, reference 23). By subsequent blotting and hybridization of this amplified DNA fragment with a synthetic oligonucleotide probe directed against the junction region of the APOE*3-Leiden gene dupli-
Table I. Clinical Characteristics of the Five apoE3-Leiden Probands at Their First Visit to the Lipid Clinic

\begin{tabular}{|c|c|c|c|c|c|}
\hline & \multicolumn{5}{|c|}{ FD probandi with apoE3-Leiden* } \\
\hline & CV & GW & $\mathbf{A B}$ & $\mathrm{JB}^{*}$ & JE \\
\hline Age & 42 & 46 & 41 & 55 & 64 \\
\hline CVD/PVD & $-1-$ & $+1-$ & $-1-$ & $-1-$ & $+1-$ \\
\hline Xanthomas $^{8}$ & + & + & + & - & - \\
\hline $\begin{array}{l}\text { Plasma cholesterol } \\
\text { ( } \mathrm{mmol} / \text { liter })\end{array}$ & 11.1 & 14.6 & 14.6 & 7.0 & 8.6 \\
\hline $\begin{array}{l}\text { Plasma triglycerides } \\
\text { ( } \mathrm{mmol} / \text { liter })\end{array}$ & 3.9 & 7.3 & 4.5 & 3.1 & 1.9 \\
\hline $\begin{array}{l}\text { VLDL-chol/TG" } \\
(\mathrm{mmol} / \mathrm{mmol})\end{array}$ & 0.8 & 0.67 & 1.38 & 1.03 & 1.74 \\
\hline $\begin{array}{l}\beta \text {-VLDL' } \\
\text { ApoE phenotype }\end{array}$ & $\begin{array}{c}+ \\
\text { E2E3-L }\end{array}$ & $\stackrel{+}{+}$ & $\stackrel{+}{+}$ & $\begin{array}{c}+ \\
\text { E3E3-L }\end{array}$ & $\stackrel{+}{+}$ \\
\hline
\end{tabular}

All five probands are excluded from these statistical calculations. Abbreviations: CVD, coronary vascular disease; E3-L, E3-Leiden; PVD, peripheral vascular disease; TG, total plasma triglycerides. * All probandi are males. ${ }^{\ddagger}$ Proband JB was on lipid-lowering drugs when first examined by us. ${ }^{8}$ Xanthomas include palmar streaks and tuberous xanthomas. "VLDL-cholesterol measured in VLDL $d<1.006$ $\mathrm{g} / \mathrm{ml}$. ' As evaluated by agarose electrophoresis in VLDL $d<1.006$ $\mathrm{g} / \mathrm{ml}$ fraction. 


\section{E3E3 E2E3L E3E3L E3E3L E3E3L E3E3L E4E3L E4E3}

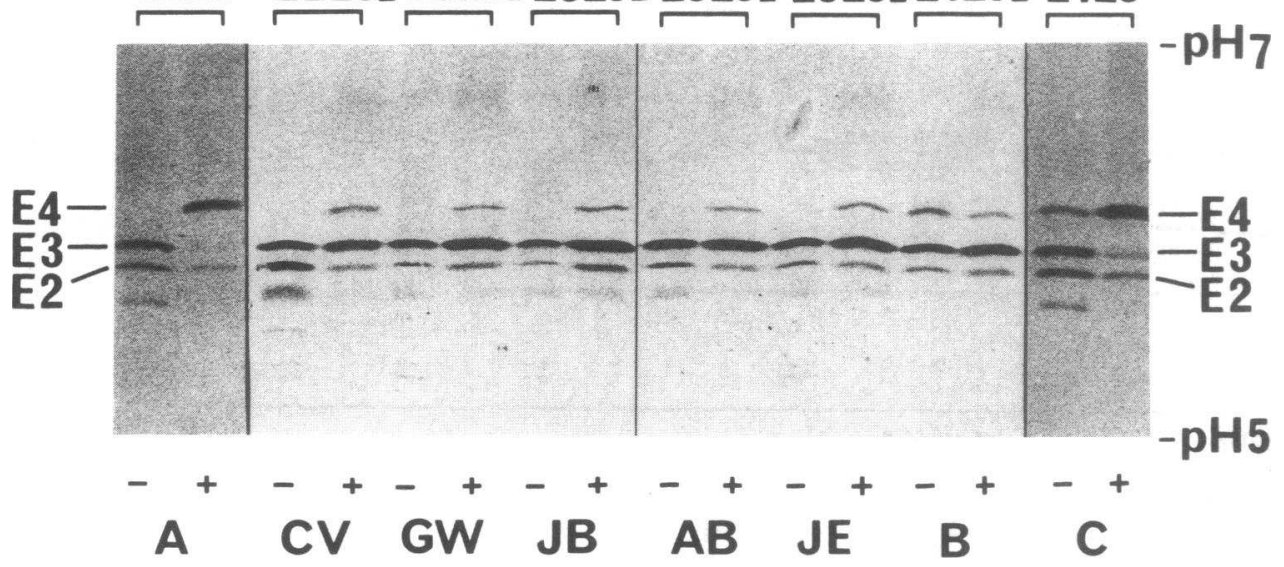

Figure 2. ApoE isoelectric focusing (pH 5-7) patterns of delipidated serum before $(-)$ and after $(+)$ cysteamine treatment of the five probands (indicated below the lane with their initials), of a family member of one of the probands (indicated with $B$ below the gel) and of two healthy control subjects (indicated with $A$ and $C$ below the gel). The corresponding apoE phenotypes are indicated above the lane. The abbreviation E3L was used to indicate the APOE*3-Leiden allele.

cation, it was shown that DNA from the probands does hybridize with this allele-specific oligonucleotide probe (Fig. $3 \mathrm{~B}$ ). Finally, digestion of this amplified DNA with HhaI restriction endonuclease followed by polyacrylamide gel electrophoresis enabled genotyping of apoE. Since the apoE3-Leiden mutation adds $21 \mathrm{bp}$ to the 72-bp Hhal fragment that is normally found in individuals with the APOE*4 allele, the resulting 93-bp HhaI fragment is typical for the APOE*3-Leiden allele (Figs. 1 and 4).

Genealogical studies. Although the five probands were ascertained independently in two different lipid clinics (Leiden and Nijmegen), we learned that they had relatives living in the same area of The Netherlands. Based on information presented to us by the probands, genealogy was done by checking the parish records from the 18 th century and the civil registration, population, and census records from the 19th and 20th centuries in a region southeast of The Hague. We learned that in this region there is no high degree of consanguinity. This genealogi-

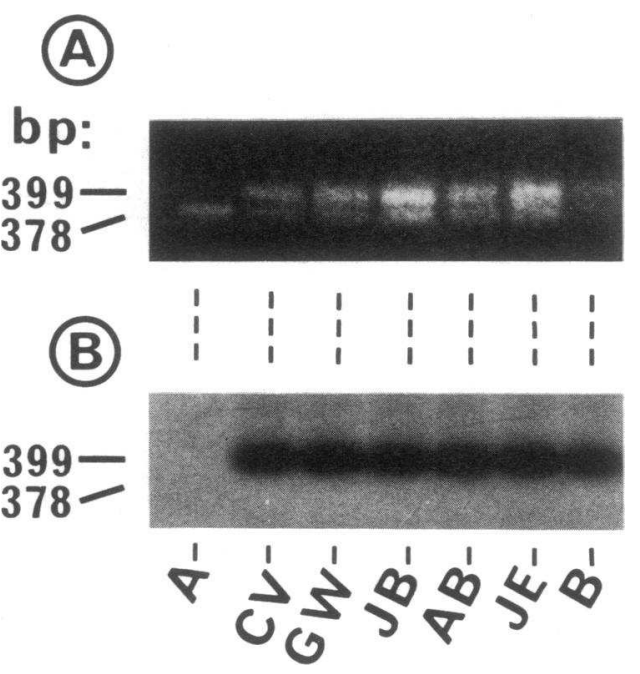

Figure 3. Agarose gel electrophoresis of PCR products using the 402/ 401 set of amplification primers followed by ethidium bromide staining $(A)$ or by hybridization with a synthetic oligonucleotide probe directed against the junction region of the E3-Leiden duplication $(B)$.

The lanes represent the five apoE3-Leiden probands (lanes $C V, G W$, $J B, A B$, and $J E$ ), a healthy control subject with apoE3E3 phenotype (lane $A$ ) and a subject with the apoE4E3-Leiden phenotype (lane $B$ ). cal study proved that the five probands share common ancestry in the seventeenth century (Fig. 5). It was found that the grandfather and grandmother of proband $\mathrm{CV}$ were related, giving the possibility of homozygosity for the E3-Leiden variant in the parental generation of this proband; the mother of proband $\mathrm{CV}$, however, was heterozygous for this variant.

Family studies. As well as the five probands, 123 family members were studied (Appendix and Fig. 5). After apoE phenotyping and genotyping, performed as described above for the probands, 37 additional individuals were found to be heterozygous for the APOE*3-Leiden allele (solid symbols in Fig. 5). In all statistical calculations the five probands were excluded in order to avoid the possibility of ascertainment bias. As indicated in Table II, there were no significant differences between the group of APOE*3-Leiden allele carriers and the group of noncarriers with respect to BMI $(P=0.656$; NS), age $(P=0.778 ; \mathrm{NS})$ and gender distribution $\left(\chi^{2}=1.020 ; P=0.315\right.$; NS). This allowed us to compare both groups with respect to lipoprotein levels without prior correction.

Agarose electrophoresis of VLDL $(d<1.006 \mathrm{~g} / \mathrm{ml})$ revealed that all carriers showed $\beta$-migrating VLDL particles, whereas $\beta$-VLDL could not be detected in any of the noncarriers (results not shown). In the group of noncarriers 14 individuals were found with more or less severe hyperlipoproteinemia other than FD based on lipoprotein analysis and agarose electrophoresis (see Appendix).

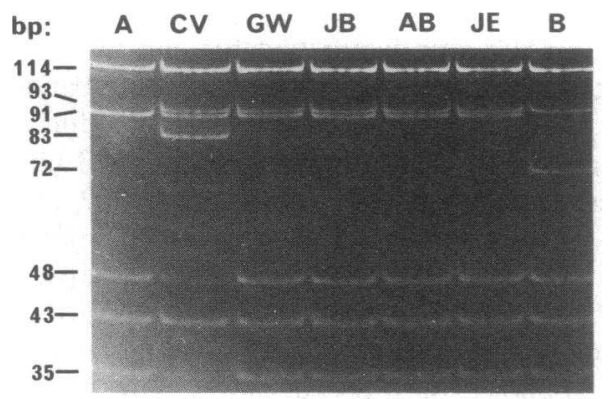

Figure 4. Polyacrylamide gel electrophoresis of PCR products using the $402 / 401$ set of amplification primers followed by Hhal restriction endonuclease digestion. The lanes represent the five apoE3-Leiden probands (lanes $C V, G W, J B, A B$, and $J E$ ), a healthy control subject with apoE3E3 phenotype (lane $A$ ) and a subject with the apoE4E3Leiden phenotype (lane $B$ ). 


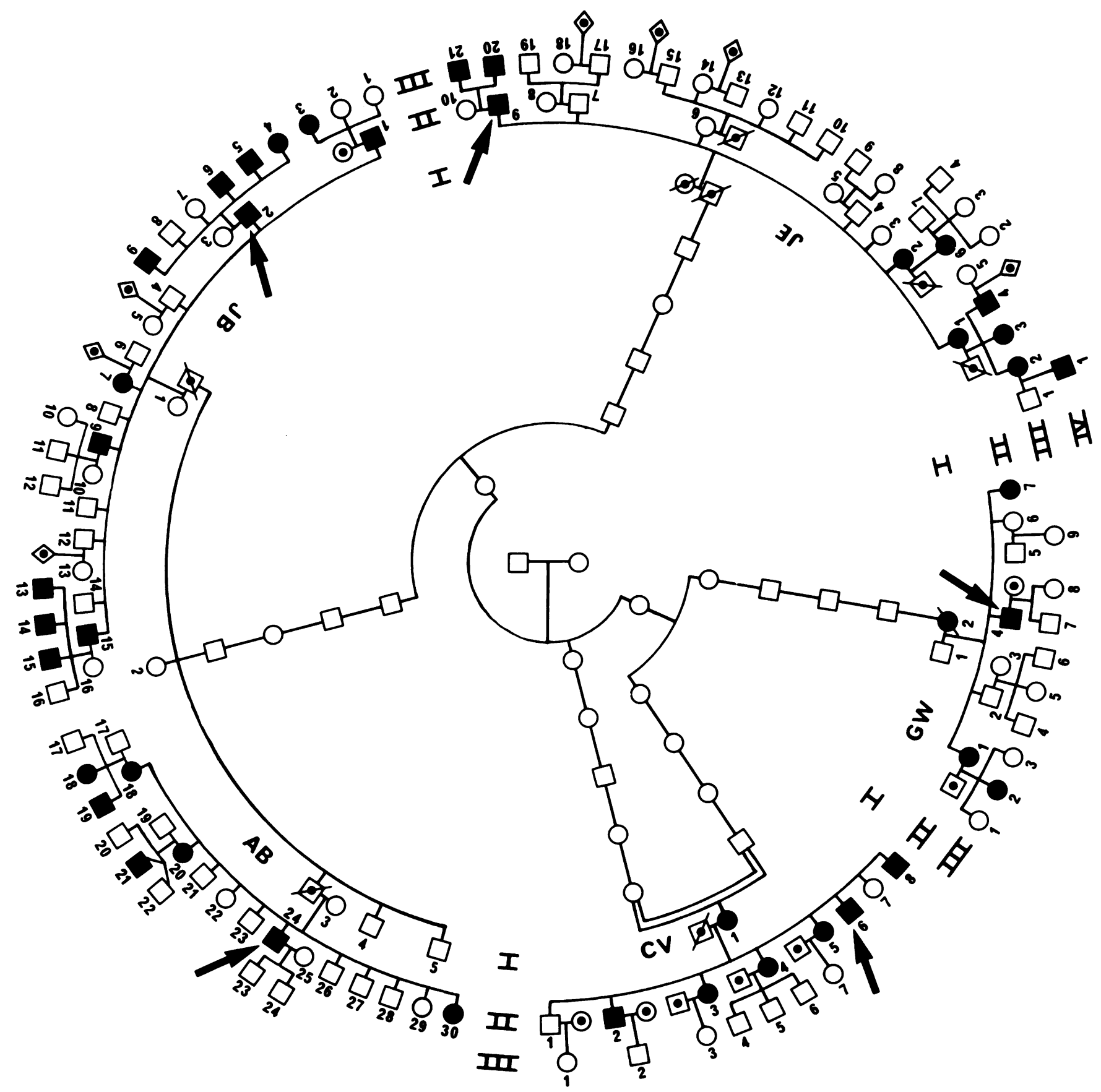

Figure 5. The extended apoE3-Leiden pedigree. I, II, III, and IV represent the successive generations. Each of the five families is indicated with the initials of the proband. The probands are indicated with an arrow. The numbering of the individuals corresponds with the numbering given in the appendix. (๑/ø) Subject (female/male) carrying the APOE*3-Leiden allele; $(\circ / \square)$ individuals not carrying the APOE*3-Leiden allele; $(\odot / \square)$ living subject, not studied; $(\odot)$ variable number of living subjects, not studied; $(\varnothing / \varnothing)$ deceased subjects, not studied. The individuals in the inner six generations (not numbered) were all deceased and could not be studied.

All mean plasma lipid and lipoprotein levels were signifcantly different between both groups (Table III). In the carriers, the ratio VLDL-cholesterol to plasma triglycerides and the plasma level of IDL-cholesterol was much higher than in the noncarrier group (mean values 0.67 vs. 0.30 and 1.41 vs. 0.24 , respectively). However, a range of overlap still exist (see Appendix). Regarding the ratio of (VLDL + IDL)-cholesterol to plasma triglycerides, the range of overlap between both groups was much smaller (see Appendix). All carriers display high plasma apoE concentrations ( $>11 \mathrm{mg} / 100 \mathrm{ml}$ ) (see Appendix). Only one individual in the group of noncarriers showed an apoE level above $11 \mathrm{mg} / 100 \mathrm{ml}$ (see Appendix).

Effect of age, BMI, and gender. From our data it is clear that there is a strong association between the presence of the APOE*3-Leiden allele and the development of FD, although there is a considerable variability in the expression of FD 
Table II. Comparison of the Group of APOE*3-Leiden Allele Carriers $(n=37)$ and Noncarriers $(n=86)$ with respect to BMI, Age, and Sex Distribution

\begin{tabular}{|c|c|c|c|c|c|}
\hline & \multicolumn{2}{|c|}{ Noncarriers } & \multicolumn{2}{|c|}{ Carriers } & \multirow[b]{2}{*}{$P^{*}$} \\
\hline & Mean & SD & Mean & SD & \\
\hline $\operatorname{BMI}\left(k g / m^{2}\right)^{\ddagger}$ & 22.8 & 3.4 & 22.8 & 3.3 & 0.656 \\
\hline Age & 39.9 & 18.6 & 39.8 & 19.8 & 0.778 \\
\hline No. of males/females & \multicolumn{2}{|c|}{$48 / 38$} & \multicolumn{2}{|c|}{$17 / 20$} & $0.315^{8}$ \\
\hline
\end{tabular}

All five probands are excluded from these statistical calculations. * $P$ value indicating the difference between the two groups as calculated with the Mann-Whitney test.

${ }^{\ddagger} \mathrm{BMI}$ represents weight/height squared.

${ }^{3} P$ value calculated by $\chi^{2}$ analysis comparing the difference in number of males and females between the two groups.

among the five probands and the other 37 APOE*3-Leiden allele carriers. Additional factors that may influence the expression of FD in E2(Arg $158 \rightarrow$ Cys) homozygotes include age, BMI, and gender (1). Since a relatively large number of APOE*3-Leiden allele carriers was available, we were able to estimate the effects of these additional factors on the expression of FD in these subjects by statistical analysis. For estimating the effect of age on plasma lipid and lipoprotein levels in the APOE*3-Leiden allele carriers and noncarriers, we divided both groups into four age subclasses: 0-19, 20-39, 40-60, and $>60 \mathrm{yr}$ old. In the group of carriers we found a strong influence of age on the ratio (VLDL + IDL)-cholesterol/plasma triglycerides and an even more pronounced effect on plasma IDL-cholesterol and plasma apoE concentration (Fig. $6 \mathrm{~A}, \mathrm{~B}$, and $C$, respectively). A similar, but much less evident, effect was found in the group of noncarriers.

Table III. Comparison of the Group of APOE*3-Leiden Allele Carriers $(n=37)$ and Noncarriers $(n=86)$ with Respect to Plasma Lipid and Lipoprotein Levels

\begin{tabular}{|c|c|c|c|c|c|}
\hline & \multicolumn{2}{|c|}{ Noncarriers } & \multicolumn{2}{|c|}{ Carriers } & \multirow[b]{2}{*}{$P^{*}$} \\
\hline & Mean & SD & Mean & SD & \\
\hline Plasma triglycerides ${ }^{\ddagger}$ & 1.48 & 1.0 & 2.24 & 0.9 & $<0.001$ \\
\hline Plasma cholesterol & 5.44 & 1.3 & 7.14 & 2.1 & $<0.001$ \\
\hline VLDL-cholesterol & 0.48 & 0.4 & 1.65 & 1.1 & $<0.001$ \\
\hline (VLDL + IDL)-cholesterol & 0.73 & 0.5 & 2.96 & 1.7 & $<0.001$ \\
\hline IDL-cholesterol & 0.24 & 0.2 & 1.41 & 0.9 & $<0.001$ \\
\hline LDL-cholesterol & 3.34 & 1.1 & 2.85 & 0.8 & 0.010 \\
\hline HDL-cholesterol & 1.43 & 0.3 & 1.33 & 0.3 & 0.034 \\
\hline \multicolumn{6}{|l|}{ VLDL-cholesterol/plasma } \\
\hline triglycerides & 0.30 & 0.1 & 0.67 & 0.2 & $<0.001$ \\
\hline \multicolumn{6}{|l|}{ (VLDL + IDL)-cholesterol/ } \\
\hline plasma triglycerides & 0.49 & 0.1 & 1.26 & 0.3 & $<0.001$ \\
\hline ApoE & 5.31 & 2.1 & 22.76 & 7.7 & $<0.001$ \\
\hline
\end{tabular}

All five probands are excluded from these statistical calculations. * $P$ value indicating the difference between the two groups as calculated with the Mann-Whitney test.

₹ All levels are given in millimoles/liter (mmol/liter) except apoE which is given in milligrams $/ 100 \mathrm{ml}$.
Both in the group of carriers and in the group of noncarriers, we found a strong linear correlation between age and BMI (Spearman's correlation coefficients of 0.61 and 0.66 for carriers and noncarriers, respectively; $P<0.001$, results not shown), indicating that BMI is strongly influenced by age. The strong influence of age on BMI is also illustrated in Fig. $6 \mathrm{D}$ for the four age subclasses for both groups. Multiple linear regression analysis was used to estimate the influence of age, BMI, and gender on the ratio (VLDL + IDL)-cholesterol/plasma triglycerides, IDL-cholesterol, and plasma apoE concentration (Table IV). It is clear that in the group of carriers, age has a strong influence on these parameters. BMI showed an additional influence on the expression of FD in this group, whereas gender had no effect.

In case of individuals with homozygosity for the E2 (Arg158 $\rightarrow$ Cys) variant, a marked difference in the onset of expression of FD exists between males and females owing to the difference in hormonal status (1). In males the FD is normally expressed between 30 and $40 \mathrm{yr}$ of age, whereas in females FD is expressed after the menopause. To investigate whether this holds true also for the APOE*3-Leiden allele carriers, we compared the plasma lipid and lipoprotein levels between male and female carriers subdivided in two age classes: $<45$ and $\geq 45 \mathrm{yr}$ of age, respectively. In both age classes no significant difference in levels of any plasma lipid and lipoprotein parameter measured was found between males and females (Table V), indicating that in the group of APOE*3-Leiden allele carriers there is no influence of gender on the age of onset of FD.

Effect of the second APOE allele. All individuals with FD found in this study are heterozygous for the APOE*3-Leiden allele and thus, they are heterozygous for a common APOE allele as well. We wondered whether this common APOE allele influences the plasma lipid and lipoprotein levels in the APOE*3-Leiden allele carriers. The results presented in Table VI show that, in the group of APOE*3-Leiden allele carriers, the $E^{*} 2$ allele enhances the expression of FD (which is reflected by the higher lipid and lipoprotein levels), whereas the $E^{*} 4$ allele showed the opposite effect. This effect is consistent with previous data obtained by Weintraub et al. (33). These results could be less evident as the number of individuals with either the E2E3-Leiden- or the E4E3-Leiden phenotype was rather small (four and three, respectively; Table VI). In addition, there could be some bias of the results since all E4E3-Leiden individuals come from one generation in a single kindred, and three of the four individuals with the E2E3-Leiden phenotype come from one generation of another kindred (see Fig. 5 and Appendix).

Irrespective of the common accompanying second allele in the $E^{*}$ 3-Leiden allele carriers, FD is dominantly inherited, i.e., the presence of normally functioning apoE molecules does not prevent the expression of FD in these subjects. To evaluate whether this might be due to a difference in distribution among the different lipoprotein fractions between apoE3-Leiden and the common apoE variant, we performed apoE phenotyping in cysteamine-treated and untreated VLDL, IDL, and HDL fractions. The cysteamine treatment enabled us to distinguish "normal" apoE (either E2, E3, or E4) from apoE3-Leiden (Fig. 2) since apoE3-Leiden contains no cysteine residues (21). As can be seen in Fig. 7 the majority of apoE protein in the VLDL and IDL density fraction consists of the apoE3-Leiden variant. In the case of both the $E^{*} 2$ and $E^{*} 3$ allele as second allele, the 

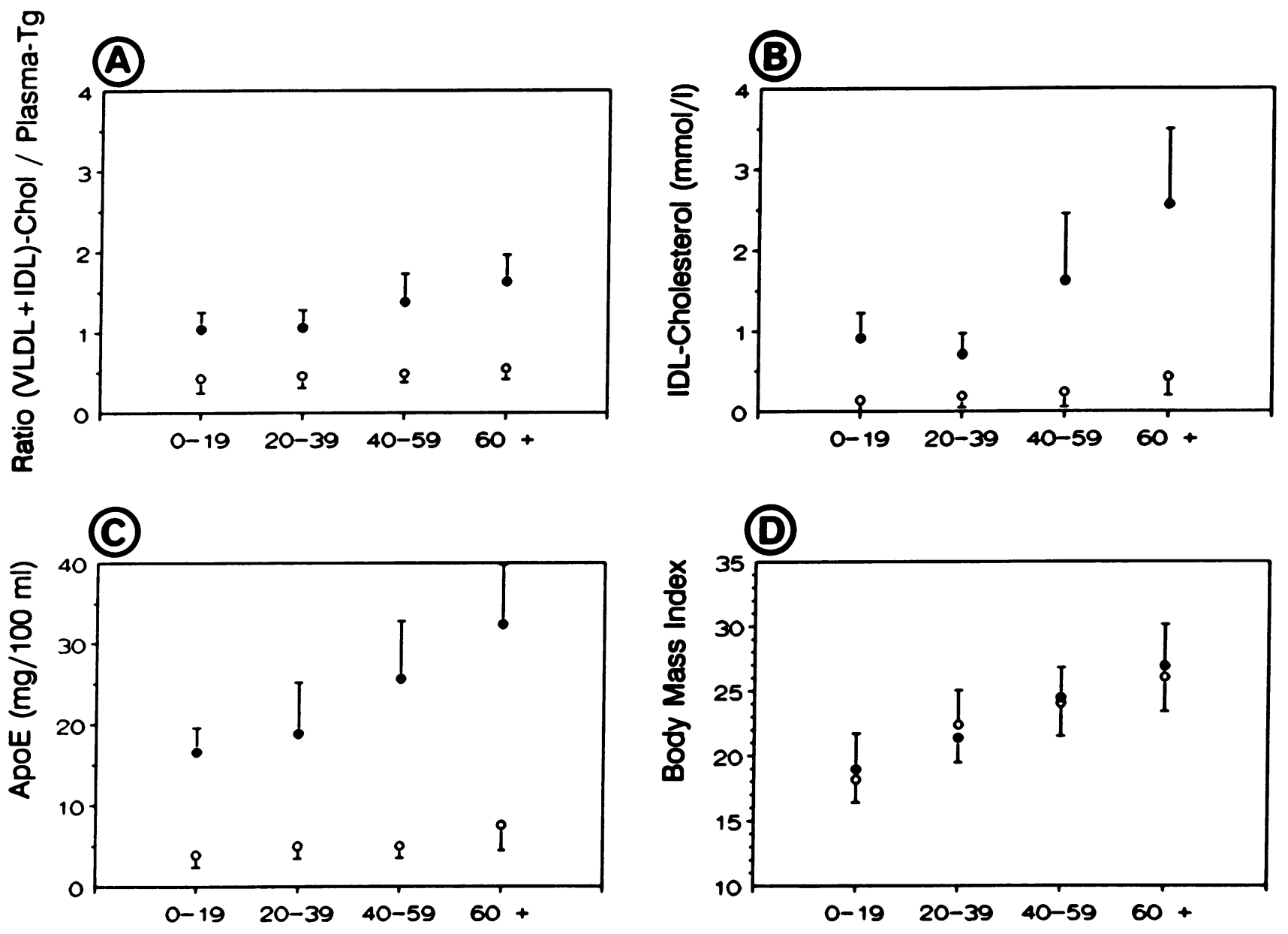

Figure 6. The ratio (VLDL + IDL)-cholesterol/plasma triglycerides $(A)$, IDL-cholesterol level $(B)$, plasma apoE level $(C)$, and BMI $(D)$ of the APOE*3-Leiden allele carriers ( $\bullet$ ) and noncarriers (O). Each individual was assigned to one of the four age classes: $0-19$ yr $(n=6$ and 10 , respectively); 20-39 yr ( $n=10$ and 34, respectively); 40-59 yr ( $n=17$ and 27, respectively); and 60 yr or older ( $n=4$ and 15, respectively). The figures between brackets in the legend represent the number of carriers and noncarriers, respectively. Mean values and standard deviation (indicated in one direction) are shown. The five probands are excluded from these calculations.

HDL density fraction is relatively enriched with the common apoE isoform as compared with its relative amount in the VLDL and IDL density fraction (Fig. 7, $A$ and $B$ ). In the case of the $E^{*} 4$ allele, the relative contribution of the $E 4$ variant to the total amount of apoE protein does not differ between the VLDL, IDL, and HDL density fraction (Fig. 7 C).

\section{Discussion}

FD has been reported earlier in association with heterozygosity for E3(Cys112 $\rightarrow$ Arg; Arg142 $\rightarrow$ Cys), E2(Lys146 $\rightarrow$ Gln), and E1-Harrisburg(Lys146 $\rightarrow$ Glu) (13-19). Both apoE3(Cys112 $\rightarrow$ Arg; Arg142 $\rightarrow$ Cys) and apoE1-Harrisburg(Lys146 $\rightarrow$ Glu) have been reported in one family each $(13,14,18)$, whereas apoE2(Lys146 $\rightarrow$ Gln) has been studied in three apparently unrelated kindreds (17). With the exception of three very lean APOE*2(Lys146 $\rightarrow$ Gln) allele carriers and one individual with the APOE*1-Harrisburg(Lys146 $\rightarrow$ Glu) allele who was on lipid-lowering diet, all family members showing heterozygosity for one of these rare mutant forms of apoE had manifest FD. Thus, for these variants FD is inherited in a dominant fashion with a high penetrance. In addition to the rare variants described above, the apoE variants E2(Arg145 $\rightarrow$ Cys) $(8,34,35)$ and E2-Christchurch(Arg1 $36 \rightarrow \operatorname{Ser})(35,36)$ are also reported to be associated with the development of FD. However, it is not known whether these mutants are associated with either a dominantly or recessively inherited form of FD, as family studies have yet to be performed.

In previous studies $(20,21)$ we have shown that dominant expression of FD also occurs in the family of an FD patient who has the apoE3-Leiden mutation. Recently, DNA and protein sequence analysis revealed that the molecular basis of apoE3-Leiden is due to a partial gene duplication leading to an in-frame insertion of 21 nucleotides forming a tandem repeat of the codons $120-126$ or $121-127(23,24)$. In this paper, four additional, apparently unrelated patients with FD carrying the APOE*3-Leiden allele in a heterozygous form were ascertained. Genealogical studies revealed that the probands share common ancestry in the 17 th century (Fig. 5). Using the families of all five probands, we were able to perform the most extensive family study thus far described with respect to a dominantly inherited form of FD. In this family study we obtained a total of 42 individuals carrying the APOE*3-Leiden allele among a total number of 128 family members. We could clearly prove that the apoE3-Leiden variant is invariably asso- 
Table IV. Multiple Linear Regression Analysis of Age, BMI, and Sex for Log-transformed Plasma Lipid and Lipoprotein Levels in the Group of APOE*3-Leiden Allele Carriers

\begin{tabular}{|c|c|c|c|c|c|}
\hline $\begin{array}{c}\text { Dependent } \\
\text { variable }\end{array}$ & $\begin{array}{l}\text { Independent } \\
\text { variable }\end{array}$ & $p^{*}$ & $r^{*}$ & $F^{*}$ & $P^{\| \prime}$ \\
\hline \multirow{4}{*}{$\begin{array}{l}\mathrm{LN}([\mathrm{VLDL}+\mathrm{IDL}]-\mathrm{cholesterol} / \\
\text { plasma triglycerides })\end{array}$} & Age & 0.71 & & & $<0.0001$ \\
\hline & BMI & -0.38 & & & 0.0273 \\
\hline & Sex' & 0.32 & & & 0.0654 \\
\hline & All variables & & 0.69 & 11.52 & $<0.0001$ \\
\hline \multirow[t]{4}{*}{ Ln(IDL-cholesterol) } & Age & 0.69 & & & 0.0001 \\
\hline & BMI & -0.28 & & & 0.1293 \\
\hline & Sex & 0.24 & & & 0.1970 \\
\hline & All variables & & 0.73 & 11.57 & $<0.0001$ \\
\hline \multirow[t]{4}{*}{$\operatorname{Ln}($ apoE $)$} & Age & 0.50 & & & 0.0029 \\
\hline & BMI & 0.01 & & & 0.9793 \\
\hline & Sex & -0.17 & & & 0.3558 \\
\hline & All variables & & 0.66 & 9.67 & $<0.0001$ \\
\hline
\end{tabular}

All five probands are excluded from these statistical calculations. ${ }^{*} p$ value represents the partial correlation coefficient. ${ }^{*} r$ value represents the multiple correlation coefficient. ${ }^{8} F$ value obtained from $F$-statistic. " $P$ value indicating the probability for $t$-statistics (partial correlation) or $F$-statistic. 'For sex, a numerical code $(1=$ females; $2=$ males $)$ was entered in this analysis.

ciated with the expression of FD in all five families, although with a variable degree of severity.

In subjects with homozygosity for apoE2(Arg158 $\rightarrow$ Cys) FD only rarely develops (1-4\%) and is commonly assumed to be highly influenced by additional factors such as age, BMI, nutritional status and gender (1). As in all subjects exhibiting heterozygosity for the APOE*3-Leiden allele express clinical symptoms of FD, we wondered whether in these subjects the expression of FD is also influenced by these additional factors. The relatively high number of FD subjects ascertained in this study ( 37 individuals in addition to the five probands), together with the absence of significant differences between the apoE3Leiden carriers and noncarriers with respect to age, BMI, and gender distribution (Table II), gave us the unique opportunity to estimate the possible association of the expression of FD with these factors by means of statistical analysis.
We found that in APOE*3-Leiden allele carriers the development of FD is strongly correlated with age (Fig. 6, $A-C$ ) as is BMI (Fig. $6 D$ ). Multiple regression analysis revealed that there was a weak effect of BMI on the expression of FD in addition to the highly significant effect of age (Table IV). Because of the strong correlation between BMI and age, part of the effect of age on the expression of FD could be derived from the effect of BMI. Although the E3-Leiden heterozygotes resembles the E2(Arg158 $\rightarrow$ Cys) homozygotes with respect to the effect of age on the expression of FD, we found that in $E^{*}$ 3-Leiden allele carriers there is, strikingly, no influence of gender on the expression and on age of onset of FD (Table V).

A number of studies conducted by Mahley and co-workers $(10,37-40)$ strongly suggest that the conformation of the 130 $150 \alpha$-helical region of apoE, the putative receptor-binding domain, can be easily modulated, leading to a change in receptor-

Table V. Comparison of Males and Females Carrying the APOE*3-Leiden Allele with Respect to Plasma Lipid and Lipoprotein Levels after Subdivision in Two Age Classes

\begin{tabular}{|c|c|c|c|c|c|c|c|c|c|c|}
\hline & \multicolumn{5}{|c|}{$<45$ yr old } & \multicolumn{5}{|c|}{$\geq 45$ yr old } \\
\hline & \multicolumn{2}{|c|}{$\begin{array}{l}\text { Males } \\
(n=13)\end{array}$} & \multicolumn{2}{|c|}{$\begin{array}{l}\text { Females } \\
(n=7)\end{array}$} & \multirow[b]{2}{*}{$P^{*}$} & \multicolumn{2}{|c|}{$\begin{array}{l}\text { Males } \\
(n=4)\end{array}$} & \multicolumn{2}{|c|}{$\begin{array}{l}\text { Females } \\
(n=13)\end{array}$} & \multirow[b]{2}{*}{$P^{*}$} \\
\hline & Mean & SD & Mean & SD & & Mean & SD & Mean & SD & \\
\hline Plasma triglycerides $^{\ddagger}$ & 2.14 & 0.77 & 1.80 & 0.66 & 0.405 & 2.30 & 0.96 & 2.57 & 0.96 & 0.610 \\
\hline Plasma cholesterol & 6.25 & 1.93 & 6.02 & 1.50 & 0.905 & 7.70 & 1.54 & 8.45 & 2.15 & 0.571 \\
\hline VLDL-cholesterol & 1.62 & 0.97 & 1.19 & 0.92 & 0.332 & 1.79 & 1.61 & 1.88 & 1.31 & 0.651 \\
\hline IDL-cholesterol & 1.05 & 0.72 & 0.73 & 0.29 & 0.342 & 1.76 & 0.36 & 1.96 & 1.05 & 0.734 \\
\hline $\begin{array}{l}\text { VLDL-cholesterol/ } \\
\text { plasma triglycerides }\end{array}$ & 0.71 & 0.21 & 0.59 & 0.27 & 0.285 & 0.68 & 0.32 & 0.68 & 0.26 & 1.000 \\
\hline (VLDL + IDL)-cholesterol/ & & & & & & & & & & \\
\hline plasma triglycerides & 1.16 & 0.33 & 1.01 & 0.22 & 0.362 & 1.52 & 0.12 & 1.43 & 0.31 & 0.308 \\
\hline ApoE & 18.45 & 4.99 & 19.88 & 6.20 & 0.501 & 21.53 & 2.23 & 29.00 & 8.03 & 0.113 \\
\hline
\end{tabular}

All five probands are excluded from these statistical calculations. $* P$ value indicating the difference between the males and females in each group as calculated with the Mann-Whitney test. ${ }^{\ddagger}$ All levels are given in millimoles/liter (mmol/liter) except apoE which is given in milligrams $/ 100 \mathrm{ml}$. 
Table VI. Comparison of the Different ApoE Phenotypes with Respect to Mean Plasma Lipid and Lipoprotein Levels in the Group of APOE*3-Leiden Allele Carriers

\begin{tabular}{|c|c|c|c|c|}
\hline & \multicolumn{3}{|c|}{ ApoE phenotype } & \multirow[b]{2}{*}{$P^{*}$} \\
\hline & E2E3-L & E3E3-L & E4E3-L & \\
\hline Number of subjects & 4 & 30 & 3 & \\
\hline Plasma triglycerides ${ }^{\ddagger}$ & 2.98 & 2.24 & 1.27 & 0.019 \\
\hline Plasma cholesterol & 9.25 & 7.07 & 5.05 & 0.025 \\
\hline VLDL-cholesterol & 2.98 & 1.58 & 0.58 & 0.024 \\
\hline (VLDL-IDL)-cholesterol & 5.01 & 2.85 & 1.25 & 0.017 \\
\hline IDL-cholesterol & 2.04 & 1.39 & 0.66 & 0.100 \\
\hline $\begin{array}{l}\text { VLDL-cholesterol/ } \\
\text { plasma triglycerides }\end{array}$ & 0.96 & 0.66 & 0.46 & 0.014 \\
\hline $\begin{array}{l}\text { (VLDL + IDL)-cholesterol/ } \\
\text { plasma triglycerides }\end{array}$ & 1.60 & 1.25 & 0.98 & 0.035 \\
\hline ApoE & 30.75 & 22.62 & 13.55 & 0.008 \\
\hline
\end{tabular}

All five probands are excluded from these statistical calculations.

* $P$ value indicating the difference between the three phenotypes as calculated with the Kruskal-Wallis test.

${ }^{\ddagger}$ All levels are given as mean values in millimoles/liter (mmol/liter) except apoE which is given in milligrams $/ 100 \mathrm{ml}$.

binding activity. For instance, an increase in receptor-binding activity of apoE2(Arg $158 \rightarrow$ Cys) can be obtained in vitro by cleavage with thrombin (38) or by cysteamine treatment (a reagent that converts cysteine to a positively charged lysine analogue) $(10,38)$. The binding activity of apoE2(Arg158 $\rightarrow$ Cys) may also be modulated in vivo to some extent, by changing the lipid composition of the lipoprotein particle (40). Their results suggest that the conformation of apoE2(Arg158 $\rightarrow$ Cys) is sensitive to its environment and that the cysteine at residue 158 has a secondary, rather than a direct, effect on receptorbinding activity. Mahley et al. (41) hypothesize that this property could explain the requirement for additional environmen-
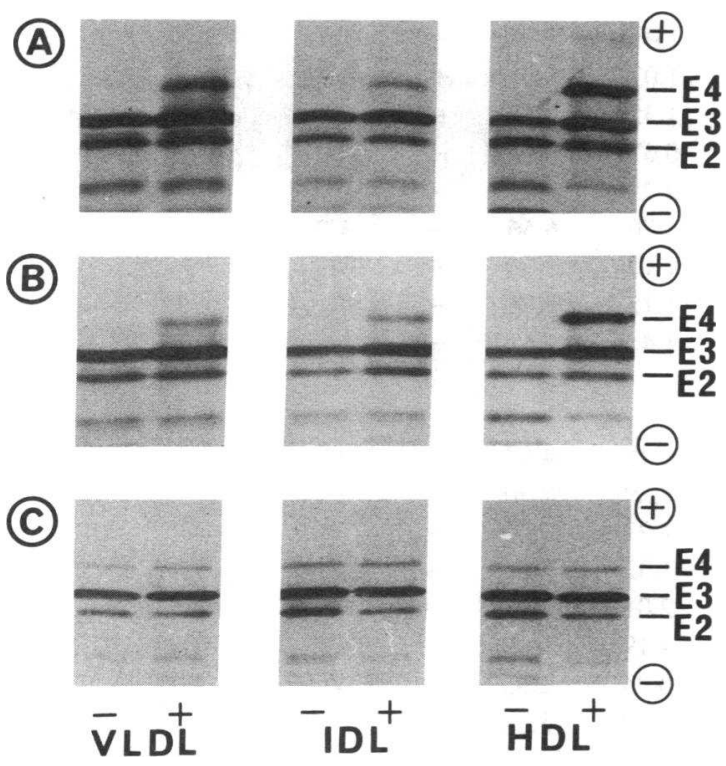

Figure 7. Isoelectric focusing pattern (pH 5-7) of VLDL, IDL, and HDL of subjects with the apoE2E3-Leiden phenotype $(A)$, the apoE3E3-Leiden phenotype $(B)$, and the apoE4E3-Leiden phenotype $(C)$ before $(-)$ and after $(+)$ cysteamine treatment. tal and/or genetic factors for the expression of FD. Only when exacerbating factors are present, does the receptor-binding activity of $\beta$-VLDL decrease and, eventually, will result in the development of FD.

In contrast to the apoE2(Arg158 $\rightarrow$ Cys) variant, the apoE variants E3(Cys112 $\rightarrow$ Arg; Arg142 $\rightarrow$ Cys), E2(Lys146 $\rightarrow$ Gln), and E1-Harrisburg(Lys146 $\rightarrow$ Glu) are almost absolutely associated with FD, even at young age (13-19). These variants have a common molecular defect, i.e., a substitution of a basic amino acid residue for a neutral or acidic residue in the predicted $\alpha$-helical receptor binding domain of apoE (residues $130-150$ ). It is suggested that the basic amino acid residues in this particular domain provide direct ionic interaction with the LDL receptor (42). Mahley et al. (41) suggest that loss of any positively charged amino acid residue within the putative $\alpha$-helical segment affects the binding of apoE by reducing the ionic interaction. This reduction probably is not easily influenced by environmental factors like lipid composition of the lipoprotein particle. As a consequence, they hypothesize that mutations in the 130-150 segment of apoE result in "permanent" receptorbinding defects. This hypothesis is sustained by experiments using apoE variants made by site-directed mutagenesis (39).

The present results convincingly show that the apoE3-Leiden variant is also invariably associated with the development of FD, although age exerts a significant effect on the severety of hyperlipidemia (Fig. 6, $A-C$ ), as in E2(Arg158 $\rightarrow$ Cys) homozygotes. Previously we have shown that apoE3-Leiden possesses a reduced receptor-binding activity $(20,21)$. Recently it was found that upon cleavage with thrombin, the $22-\mathrm{kD}$ fragment of apoE3-Leiden possesses a nearly normal binding activity (23). This suggests that, owing to the insertion of seven amino acids, close to the receptor-binding domain, and constituting nearly two turns of the $\alpha$-helix, the structure of the entire protein is changed in such a way that the carboxyl-terminal domain irreversibly prevents the receptor-binding region of apoE to interact with the LDL receptor, and as a consequence, interferes with the binding activity, the latter being sensitive to environmental factors such as age.

ApoE3-Leiden, described in this paper, as well as the E3(Cys1 $12 \rightarrow$ Arg; Arg142 $\rightarrow$ Cys), E2(Lys146 $\rightarrow$ Gln), and E1-Harrisburg(Lys146 $\rightarrow$ Glu), represent binding-defective apoE mutants that are associated with dominantly inherited FD, i.e., the subjects who are heterozygous for these variant alleles display FD, irrespective of the presence of normal apoE molecules. In that chylomicron and VLDL remnants possess several apoE molecules per particle, it may be expected that both normal and mutant apoE molecules are present on each particle. This raises the question as to why the normal apoE molecules do not prevent the expression of FD in these subjects. Mahley et al. (41) postulates two mechanisms for the phenomenon of dominantly inherited FD: $(a)$ the mutant apoE disrupts the organization of the apoE molecules on the surface of the lipoprotein, including that of the normal apoE molecules; $(b)$ the presence of defective apoE molecules reduce the effective concentration of active apoE molecules on the surface of the particles, thereby reducing its affinity for the receptor. There is some evidence that plasma levels of apoF may become rate-limiting in the clearance of remnant lipoproteins (43). Thus, a low efficient concentration of normally active apoE molecules on the remnant particles might be the underlying molecular defect of dominantly inherited forms of FD.

In subjects with the E3(Cys112 $\rightarrow$ Arg; Arg142 $\rightarrow$ Cys) 
variant, equal amounts of normal and variant apoE3 were found in the VLDL density fraction (14). In contrast, our results clearly show that in plasma of all apoE3-Leiden subjects, the apoE3-Leiden variant largely predominates over its normal apoE counterpart (Fig. 2). Preliminary results, obtained by quantitative isoelectric focusing/immunoblotting using ${ }^{125} \mathrm{I}$-labeled rabbit anti-goat anti-apoE antibodies followed by counting the radioactivity in the respective bands after cysteamine modification, showed that $\sim 75 \%$ of the total plasma apoE consists of apoE3-Leiden (results not shown). Separate analysis of the different lipoprotein fractions revealed that this predominance is most pronounced in the VLDL and IDL density fractions (Fig. 7), except in the case of apoE4 as the normal variant. ApoE4 distributes preferentially to VLDL (44), which should be ascribed to the arginine at residue $112(45)$. Similarly, the preferential association of apoE3-Leiden with VLDL and IDL density fractions may be apoE3-Leiden is apoE4-like in that it contains arginine at residue 112 . In fact, this predomination of apoE3-Leiden renders the chylomicron and VLDL remnants into "apparent" homozygosity for apoE3-Leiden. Whether the "extent of homozygosity," i.e., the relative amount of active apoE on these particles is associated with the degree of severity of FD expression is currently under investigation. We found that the APOE*2(Arg158 $\rightarrow$ Cys) allele as second allele in apoE3-Leiden subjects enhances the expression of $F D$, whereas the opposite was true for the APOE*4(Cys112 $\rightarrow$ Arg) allele (Table VI). This observation indicates that the second common APOE allele in apoE3-Leiden subjects does influence the development of FD.

The present paper reinforces the concept that FD is a genetically heterogeneous disease entity with a recessive mode of inheritance in case of the common E2(Arg158 $\rightarrow$ Cys) variant and with a dominantly inherited form in case of rare apoE mutants. It is shown that these dominantly inherited forms of FD display high rates of penetrance, making early diagnosis in these families feasible. From a clinical point of view, we recommend that all patients with elevated plasma cholesterol and triglyceride levels concomitant with increased cholesterol/triglyceride ratios in the VLDL fraction be analyzed for apoE phenotype and/or genotype. In case of E2E2 homozygosity this analysis will only sustain the FD diagnosis. However, when suspected FD patients do not exhibit the common E2E2 homozygosity, the patients might carry a rare APOE allele, and thus family studies are indicated.

\section{APPENDIX}

Individual Data

\begin{tabular}{|c|c|c|c|c|c|c|c|c|c|c|c|c|c|c|c|}
\hline No. & BMI & Age & Sex & $\begin{array}{c}\text { Plasma } \\
\text { triglycerides }\end{array}$ & $\begin{array}{c}\text { Plasma } \\
\text { cholesterol }\end{array}$ & $\begin{array}{c}\text { VLDL- } \\
\text { cholesterol }\end{array}$ & Ratio & $\begin{array}{c}\text { IDL- } \\
\text { cholesterol }\end{array}$ & $\begin{array}{c}\text { LDL- } \\
\text { cholesterol }\end{array}$ & $\begin{array}{c}\text { HDL- } \\
\text { cholesterol }\end{array}$ & $\begin{array}{c}\text { Plasma } \\
\text { ApoE }\end{array}$ & $\beta$-VLDL & $\begin{array}{c}\text { ApoE } \\
\text { phenotype }\end{array}$ & $\begin{array}{c}\text { Clinical } \\
\text { symptoms }\end{array}$ & Remarks \\
\hline & $\mathrm{kg} / \mathrm{m}^{2}$ & $y r$ & & & & & ol//lit & & & & $m g / d l$ & & & & \\
\hline
\end{tabular}

Family proband CV

\begin{tabular}{|c|c|c|c|c|c|c|c|c|c|c|c|c|c|c|c|}
\hline I-1 & 22.4 & 82 & $\mathbf{F}$ & 2.50 & 10.28 & 1.35 & 1.97 & 3.58 & 3.98 & 1.37 & 34.37 & + & $3 / 3 L^{*}$ & $\mathbf{X}$ & III \\
\hline II-1 & 24.9 & 60 & $\mathbf{M}$ & 4.07 & 7.15 & 1.32 & 0.51 & 0.74 & 3.92 & 1.17 & 9.75 & - & $3 / 3$ & & II \\
\hline II-2 & 24.0 & 57 & $\mathbf{M}$ & 2.27 & 7.85 & 1.26 & 1.49 & 2.13 & 3.47 & 0.99 & 23.14 & + & $3 / 3 \mathrm{~L}$ & $\mathrm{X}, \mathrm{C}$ & III, Med \\
\hline II-3 & 19.4 & 55 & $\mathbf{F}$ & 4.25 & 12.82 & 5.11 & 2.05 & 3.62 & 2.77 & 1.32 & 39.69 & + & $2 / 3 \mathrm{~L}$ & & III \\
\hline II-4 & 23.2 & 52 & $\mathbf{F}$ & 1.48 & 6.59 & 1.24 & 1.40 & 0.83 & 2.83 & 1.69 & 19.26 & + & $2 / 3 \mathrm{~L}$ & $\mathbf{X}$ & III, Med \\
\hline II-5 & 22.1 & 50 & $\mathrm{~F}$ & 3.63 & 10.43 & 3.16 & 1.60 & 2.66 & 3.43 & 1.18 & 35.93 & + & $2 / 3 \mathrm{~L}$ & & III \\
\hline II-6 & 21.5 & 48 & $\mathbf{M}$ & 2.82 & 6.74 & 2.30 & 1.01 & 0.55 & 2.77 & 1.12 & 23.35 & + & $2 / 3 \mathrm{~L}$ & $\mathbf{X}$ & III, Med \\
\hline II-7 & 22.0 & 46 & $\mathrm{~F}$ & 1.13 & 5.75 & 0.37 & 0.62 & 0.33 & 3.62 & 1.43 & 4.81 & - & $3 / 3$ & & \\
\hline II-8 & 23.0 & 44 & $\mathbf{M}$ & 2.18 & 7.99 & 1.78 & 1.56 & 1.63 & 3.51 & 1.07 & 23.24 & + & $3 / 3 \mathrm{~L}$ & $\mathbf{X}$ & III \\
\hline III-1 & 20.4 & 34 & $\mathbf{F}$ & 1.48 & 5.48 & 0.38 & 0.51 & 0.37 & 3.38 & 1.35 & 5.97 & - & $3 / 3$ & & \\
\hline III-2 & 24.7 & 25 & $\mathbf{M}$ & 3.09 & 4.90 & 1.09 & 0.44 & 0.26 & 2.88 & 0.67 & 3.99 & - & $3 / 3$ & & \\
\hline III-3 & 20.3 & 23 & $\mathrm{~F}$ & 1.09 & 5.47 & 0.21 & 0.39 & 0.21 & 2.80 & 2.25 & 7.43 & - & $4 / 2$ & & \\
\hline III-4 & & 28 & $\mathbf{M}$ & 1.03 & 4.89 & 0.33 & 0.72 & 0.41 & 2.45 & 1.70 & 6.56 & - & $3 / 2$ & & \\
\hline III-5 & 22.0 & 23 & $\mathbf{M}$ & 0.90 & 3.88 & 0.35 & 0.42 & 0.03 & 2.38 & 1.12 & 3.96 & - & $3 / 2$ & & \\
\hline III-6 & 20.4 & 19 & $\mathbf{M}$ & 0.64 & 3.48 & 0.20 & 0.34 & 0.02 & 2.11 & 1.15 & 5.06 & - & $4 / 2$ & & \\
\hline III-7 & 22.6 & 21 & $\mathbf{F}$ & 0.75 & 3.97 & 0.24 & 0.39 & 0.05 & 2.27 & 1.41 & 7.41 & - & $4 / 2$ & & \\
\hline \multicolumn{16}{|c|}{ Family proband GW } \\
\hline I-1 & & 82 & $\mathbf{M}$ & 1.21 & 4.78 & 0.37 & 0.41 & 0.13 & 2.83 & 1.45 & 4.07 & - & $3 / 3$ & & \\
\hline I-2 & & 78 & $\mathbf{F}$ & 3.32 & 9.95 & 2.72 & 1.50 & 2.27 & 3.67 & 1.29 & 27.90 & + & $3 / 3 \mathrm{~L}$ & $\mathrm{C}$ & III \\
\hline II-1 & 27.0 & 51 & $\mathbf{F}$ & 1.44 & 8.67 & 0.66 & 1.27 & 1.17 & 4.91 & 1.93 & 30.02 & + & $3 / 3 \mathrm{~L}$ & & III \\
\hline II-2 & 20.7 & 47 & $\mathbf{M}$ & 1.69 & 5.37 & 0.40 & 0.47 & 0.39 & 3.26 & 1.32 & 3.85 & - & $3 / 3$ & & \\
\hline II-3 & 20.3 & 45 & $\mathbf{F}$ & 1.02 & 5.37 & 0.21 & 0.58 & 0.38 & 2.77 & 2.01 & 3.16 & - & $3 / 3$ & & \\
\hline II-4 & 26.8 & 46 & $\mathbf{M}$ & 3.55 & 7.77 & 2.07 & 1.03 & 1.60 & 2.91 & 1.19 & 22.39 & + & $3 / 3 \mathrm{~L}$ & $\mathrm{X}, \mathrm{C}$ & III, Med \\
\hline II-5 & 26.3 & 41 & $\mathbf{M}$ & 2.93 & 5.41 & 0.76 & 0.34 & 0.24 & 3.47 & 0.94 & 2.53 & - & $4 / 3$ & & \\
\hline II-6 & 25.6 & 43 & $\mathbf{F}$ & 1.83 & 4.81 & 0.37 & 0.67 & 0.85 & 2.06 & 1.53 & 5.54 & - & $3 / 3$ & & \\
\hline II-7 & & 40 & $\mathbf{F}$ & 1.43 & 4.96 & 0.53 & 0.78 & 0.58 & 2.82 & 1.03 & 18.32 & + & $3 / 3 \mathrm{~L}$ & & III \\
\hline III-1 & 26.4 & 28 & $\mathbf{F}$ & 0.96 & 4.80 & 0.15 & 0.31 & 0.15 & 2.70 & 1.80 & 4.36 & - & $3 / 3$ & & \\
\hline III-2 & 20.1 & 24 & $\mathrm{~F}$ & 1.52 & 5.33 & 0.39 & 0.91 & 0.99 & 2.35 & 1.60 & 15.99 & + & $3 / 3 \mathrm{~L}$ & & III \\
\hline III-3 & 16.8 & 19 & $\mathbf{F}$ & 0.63 & 3.96 & 0.15 & 0.25 & 0.01 & 2.06 & 1.74 & 7.12 & - & $3 / 3$ & & \\
\hline III-4 & 20.3 & 21 & $\mathbf{M}$ & 2.42 & 5.08 & 0.69 & 0.40 & 0.28 & 2.99 & 1.12 & 5.03 & - & $3 / 3$ & & \\
\hline
\end{tabular}


Family proband GW (Continued)

\begin{tabular}{|c|c|c|c|c|c|c|c|c|c|c|c|c|c|c|c|}
\hline No. $\mathrm{B}$ & BMI A & Age & Sex & $\begin{array}{c}\text { Plasma } \\
\text { triglycerides }\end{array}$ & $\begin{array}{c}\text { Plasma } \\
\text { cholesterol }\end{array}$ & $\begin{array}{l}\text { VLDL- } \\
\text { cholesterol }\end{array}$ & Ratio & $\begin{array}{c}\text { IDL- } \\
\text { cholesterol }\end{array}$ & $\begin{array}{c}\text { LDL- } \\
\text { cholesterol }\end{array}$ & $\begin{array}{c}\text { HDL- } \\
\text { cholesterol }\end{array}$ & $\begin{array}{l}\text { Plasma } \\
\text { ApoE }\end{array}$ & $\beta$-VLDL & $\begin{array}{c}\text { ApoE } \\
\text { phenotype }\end{array}$ & $\begin{array}{c}\text { Clinical } \\
\text { symptoms }\end{array}$ & Remarks \\
\hline III-5 & 20.5 & $5 \quad 18$ & $8 \quad F$ & 1.32 & 3.28 & 0.33 & 0.26 & 0.01 & 1.73 & 1.21 & 2.95 & - & $3 / 3$ & & \\
\hline III-6 & 17.4 & $4 \quad 17$ & $7 \quad \mathbf{M}$ & 0.74 & 3.20 & 0.21 & 0.35 & 0.05 & 1.57 & 1.37 & 2.64 & - & $3 / 3$ & & \\
\hline III-7 & 21.5 & 22 & $\mathbf{M}$ & 2.14 & 5.36 & 0.69 & 0.42 & 0.20 & 3.32 & 1.15 & 3.26 & - & $4 / 3$ & & \\
\hline III-8 & 24.9 & 21 & $F$ & 1.70 & 6.18 & 0.55 & 0.47 & 0.25 & 3.65 & 1.73 & 3.61 & - & $4 / 3$ & & \\
\hline III-9 & 17.6 & 19 & $\mathrm{~F}$ & 2.25 & 6.16 & 0.69 & 0.32 & 0.03 & 4.13 & 1.31 & 3.58 & - & $3 / 3$ & & \\
\hline \multicolumn{16}{|c|}{ Family proband JE } \\
\hline II-1 & 30.1 & 80 & $F$ & 3.92 & 9.04 & 2.10 & 1.43 & 3.51 & 2.31 & 1.12 & 44.11 & + & $3 / 3 \mathrm{~L}$ & & III \\
\hline II-2 & 27.7 & 74 & $4 \quad F$ & 2.28 & 7.04 & 1.04 & 1.26 & 1.83 & 3.10 & 1.07 & 30.45 & + & $3 / 3 \mathrm{~L}$ & & III \\
\hline II-3 & 26.8 & 373 & $3 \quad F$ & 1.79 & 6.02 & 0.71 & 0.62 & 0.40 & 3.75 & 1.16 & 9.47 & - & $3 / 3$ & & \\
\hline II-4 & 24.7 & $7 \quad 71$ & $1 \quad M$ & 1.44 & 5.92 & 0.48 & 0.57 & 0.34 & 3.94 & 1.16 & 7.55 & - & $3 / 3$ & & \\
\hline II-5 & 26.9 & 70 & F & 5.80 & 8.29 & 2.91 & 0.63 & 0.75 & 3.59 & 1.04 & 15.70 & - & $4 / 3$ & & II \\
\hline II-6 & 27.5 & 70 & $F$ & 1.04 & 5.30 & 0.18 & 0.52 & 0.36 & 3.22 & 1.54 & 9.84 & - & $3 / 3$ & & \\
\hline II-7 & 23.5 & 68 & $\mathbf{M}$ & 0.98 & 6.11 & 0.21 & 0.52 & 0.30 & 3.92 & 1.68 & 8.99 & - & $3 / 3$ & & \\
\hline II-8 & 24.9 & 65 & $5 \quad \mathrm{~F}$ & 3.43 & 9.40 & 0.96 & 0.55 & 0.91 & 6.18 & 1.35 & 9.09 & - & $4 / 3$ & & II \\
\hline II-9 & 27.4 & 64 & $4 \quad M$ & 1.99 & 8.62 & 2.37 & 2.01 & 1.62 & 3.42 & 1.21 & 25.09 & + & $3 / 3 \mathrm{~L}$ & $\mathrm{C}$ & III \\
\hline II-10 & & 62 & F & 2.44 & 6.06 & 0.82 & 0.45 & 0.27 & 3.67 & 1.30 & 5.24 & - & $3 / 3$ & & \\
\hline III-1 & 28.4 & 52 & $\mathbf{M}$ & 3.52 & 6.48 & 1.33 & 0.37 & & 3.90 & 1.29 & 6.24 & - & $3 / 3$ & & II \\
\hline III-2 & 26.5 & 47 & $\mathrm{~F}$ & 1.68 & 5.46 & 0.42 & 0.92 & 1.12 & 1.94 & 1.98 & 18.24 & + & $3 / 3 \mathrm{~L}$ & & III \\
\hline III-3 & 24.2 & 42 & $F$ & 1.87 & 6.01 & 1.35 & 1.01 & 0.54 & 2.50 & 1.62 & 22.21 & + & $3 / 3 \mathrm{~L}$ & & III \\
\hline III-4 & 25.2 & 46 & $\mathbf{M}$ & 1.82 & 6.46 & 1.20 & 1.38 & 1.31 & 2.60 & 1.35 & 20.71 & + & $3 / 3 \mathrm{~L}$ & & III \\
\hline III-5 & 30.4 & 40 & $F$ & 0.82 & 5.74 & 0.27 & 0.35 & 0.02 & 3.89 & 1.56 & 4.13 & - & $4 / 2$ & & \\
\hline III-6 & 26.1 & 46 & $F$ & 2.22 & 5.85 & 1.35 & 1.09 & 1.06 & 2.32 & 1.12 & 23.03 & + & $3 / 3 \mathrm{~L}$ & & III, Med \\
\hline III-7 & 23.8 & 49 & $\mathbf{M}$ & 5.18 & 5.20 & 1.56 & 0.36 & 0.32 & 2.56 & 0.76 & 7.78 & - & $4 / 4$ & & IV \\
\hline III-8 & 22.6 & 45 & $F$ & 1.25 & 6.00 & 0.39 & 0.54 & 0.29 & 3.84 & 1.48 & 5.15 & - & $4 / 3$ & & \\
\hline III-9 & 22.3 & 41 & $\mathbf{M}$ & 1.51 & 5.35 & 0.56 & 0.51 & 0.21 & 2.88 & 1.70 & 6.48 & - & $3 / 3$ & & \\
\hline III-10 & 25.9 & 43 & $\mathbf{M}$ & 1.01 & 5.26 & 0.38 & 0.64 & 0.27 & 3.23 & 1.38 & 4.87 & - & $4 / 3$ & & \\
\hline III-11 & 21.4 & 36 & $\mathbf{M}$ & 0.54 & 2.68 & 0.07 & 0.54 & 0.22 & 1.57 & 0.82 & 4.89 & - & $3 / 3$ & & \\
\hline III-12 & & 33 & $F$ & 1.14 & 4.08 & 0.43 & 0.41 & 0.04 & 2.32 & 1.29 & 4.19 & - & $4 / 3$ & & \\
\hline III- 13 & 23.5 & 39 & $\mathbf{M}$ & 2.24 & 5.96 & 0.89 & 0.58 & 0.40 & 3.59 & 1.08 & 4.22 & - & $4 / 3$ & & \\
\hline III-14 & 21.2 & 37 & $\mathrm{~F}$ & 0.67 & 4.20 & 0.22 & 0.49 & 0.11 & 2.21 & 1.66 & 3.47 & - & $4 / 3$ & & \\
\hline III-15 & 22.0 & 40 & $\mathbf{M}$ & 0.52 & 4.56 & 0.18 & 0.65 & 0.16 & 2.63 & 1.59 & 5.60 & - & $4 / 3$ & & \\
\hline III-16 & 21.5 & 38 & $F$ & 0.58 & 5.74 & 0.24 & 0.66 & 0.14 & 3.66 & 1.70 & 6.54 & - & $3 / 3$ & & \\
\hline III-17 & 23.4 & 41 & $\mathbf{M}$ & 1.96 & 8.87 & 0.57 & 0.51 & 0.42 & 6.45 & 1.43 & 7.48 & - & $4 / 3$ & & II \\
\hline III- 18 & 29.4 & 38 & $F$ & 1.09 & 6.79 & 0.36 & 0.40 & 0.08 & 4.86 & 1.49 & 6.24 & - & $4 / 3$ & & \\
\hline III-19 & 22.3 & 38 & $\mathbf{M}$ & 0.70 & 4.58 & 0.13 & 0.54 & 0.25 & 2.41 & 1.79 & 7.14 & - & $3 / 3$ & & \\
\hline III-20 & 21.7 & 33 & $\mathbf{M}$ & 1.87 & 4.94 & 1.52 & 1.06 & 0.47 & 1.88 & 1.07 & 18.14 & + & $3 / 3 \mathrm{~L}$ & & III \\
\hline III-21 & 23.3 & 30 & $\mathbf{M}$ & 1.86 & 6.25 & 1.83 & 1.41 & 0.80 & 2.48 & 1.14 & 17.89 & + & $3 / 3 \mathrm{~L}$ & & III \\
\hline IV-1 & 20.5 & 19 & $\mathbf{M}$ & 2.69 & 5.84 & 2.13 & 1.04 & 0.66 & 1.92 & 1.13 & 17.73 & + & $3 / 3 \mathrm{~L}$ & & III \\
\hline IV-2 & & 24 & $\mathbf{M}$ & 1.14 & 5.70 & 0.60 & 0.55 & 0.03 & 3.78 & 1.29 & 6.57 & - & $4 / 3$ & & \\
\hline IV-3 & 21.5 & 23 & F & 1.79 & 6.56 & 0.53 & 0.41 & 0.21 & 3.74 & 2.08 & 6.91 & - & $4 / 3$ & & \\
\hline IV-4 & & 20 & $\mathbf{M}$ & 3.67 & 4.51 & 0.84 & 0.28 & 0.18 & 2.45 & 1.04 & 6.26 & - & $4 / 3$ & & \\
\hline \multicolumn{16}{|c|}{ Family probandi $A B$ and $J B$} \\
\hline I-1 & 25.7 & 83 & $\mathrm{~F}$ & 1.30 & 5.27 & 0.28 & 0.45 & 0.31 & 3.28 & 1.40 & 4.29 & - & $3 / 3$ & & \\
\hline $\mathrm{I}-2$ & 25.4 & 85 & $\mathbf{F}$ & 1.60 & 7.68 & 0.57 & 0.46 & 0.16 & 5.75 & 1.20 & 6.48 & - & $4 / 3$ & & II, Med \\
\hline I-3 & 33.1 & 74 & $\mathbf{F}$ & 2.61 & 6.38 & 0.99 & 0.50 & 0.32 . & 3.41 & 1.66 & 7.09 & - & $3 / 3$ & & Med \\
\hline $\mathrm{I}-4$ & 24.8 & 72 & $\mathbf{M}$ & 2.04 & 8.52 & 0.85 & 0.63 & 0.44 & 6.11 & 1.12 & 4.47 & - & $4 / 3$ & & II \\
\hline I-5 & 27.8 & 71 & $\mathbf{M}$ & 3.03 & 6.79 & 1.20 & 0.50 & 0.33 & 4.44 & 0.82 & 7.09 & - & $4 / 3$ & & \\
\hline II-1 & 24.1 & 56 & $\mathbf{M}$ & 3.65 & 9.82 & 4.15 & 1.67 & 1.93 & 2.95 & 0.79 & 23.53 & + & $3 / 3 \mathrm{~L}$ & & III \\
\hline II-2 & 25.4 & 55 & $\mathbf{M}$ & 3.14 & 7.06 & 1.80 & 1.28 & 2.23 & 2.00 & 1.03 & 30.07 & + & $3 / 3 \mathrm{~L}$ & & III, Med \\
\hline II-3 & 25.3 & 49 & $\mathbf{F}$ & 0.53 & 4.90 & 0.09 & 0.28 & 0.06 & 3.07 & 1.68 & 2.59 & - & $4 / 3$ & & \\
\hline II-4 & 24.5 & 53 & $\mathbf{M}$ & 0.60 & 4.74 & 0.12 & 0.53 & 0.20 & 3.15 & 1.27 & 4.25 & - & $4 / 3$ & & \\
\hline II-5 & 22.5 & 52 & $\mathrm{~F}$ & 1.17 & 6.11 & 0.20 & 0.38 & 0.25 & 3.61 & 2.05 & 6.98 & - & $3 / 3$ & & \\
\hline II-6 & 22.5 & 69 & $\mathbf{M}$ & 0.82 & 4.52 & 0.11 & 0.96 & 0.68 & 2.71 & 1.02 & 3.91 & - & $4 / 2$ & & \\
\hline II-7 & 28.7 & 52 & $F$ & 1.59 & 6.24 & 0.69 & 1.27 & 1.33 & 2.74 & 1.48 & 19.28 & + & $3 / 3 \mathrm{~L}$ & & III, Med \\
\hline II-8 & 24.2 & 51 & $\mathbf{M}$ & 1.93 & 6.23 & 0.62 & 0.57 & 0.48 & 3.56 & 1.57 & 4.17 & - & $4 / 3$ & & \\
\hline II-9 & 20.8 & 47 & $\mathbf{M}$ & 1.44 & 6.68 & 0.55 & 1.53 & 1.65 & 3.15 & 1.33 & 18.76 & + & $3 / 3 \mathrm{~L}$ & & III \\
\hline II- 10 & 22.7 & 49 & $\mathbf{F}$ & 1.02 & 5.66 & 0.23 & 0.42 & 0.20 & 3.80 & 1.43 & 6.10 & - & $4 / 3$ & & \\
\hline II-11 & 23.5 & 44 & $\mathbf{M}$ & 1.20 & 5.28 & 0.37 & 0.41 & 0.12 & 3.33 & 1.46 & 5.12 & - & $4 / 3$ & & \\
\hline
\end{tabular}




\begin{tabular}{|c|c|c|c|c|c|c|c|c|c|c|c|c|c|c|c|}
\hline No. Bl & MI Age & Sex & & $\begin{array}{l}\text { Plasma } \\
\text { riglycerides }\end{array}$ & $\begin{array}{c}\text { Plasma } \\
\text { cholesterol }\end{array}$ & $\begin{array}{l}\text { VLDL- } \\
\text { cholesterol }\end{array}$ & Ratio & $\begin{array}{c}\text { IDL- } \\
\text { cholesterol }\end{array}$ & $\begin{array}{c}\text { LDL- } \\
\text { cholesterol }\end{array}$ & $\begin{array}{c}\text { HDL } \\
\text { cholesterol }\end{array}$ & $\begin{array}{l}\text { Plasma } \\
\text { ApoE }\end{array}$ & $\beta$-VLDL & $\begin{array}{c}\text { ApoE } \\
\text { phenotype }\end{array}$ & $\begin{array}{l}\text { Clinical } \\
\text { symptoms }\end{array}$ & Remarks \\
\hline II-12 & 21.3 & 46 & $\mathbf{M}$ & 0.65 & 5.53 & 0.21 & 0.58 & 0.17 & 3.87 & 1.28 & 4.52 & - & $4 / 3$ & & \\
\hline II-13 & & 41 & $F$ & 0.69 & 5.21 & 0.16 & 0.30 & 0.05 & 3.02 & 1.98 & 3.50 & - & $4 / 3$ & & \\
\hline II-14 & 24.6 & 42 & $\mathbf{M}$ & 2.16 & 4.34 & 0.67 & 0.40 & 0.20 & 2.60 & 0.87 & 3.54 & - & $4 / 3$ & & \\
\hline II-15 & 26.3 & 40 & $\mathbf{M}$ & 2.52 & 10.05 & 1.97 & 1.94 & 2.93 & 3.93 & 1.22 & 27.25 & + & $3 / 3 \mathrm{~L}$ & & III \\
\hline II-16 & 24.7 & 37 & $\mathbf{F}$ & 1.17 & 5.29 & 0.21 & 0.34 & 0.19 & 2.83 & 2.06 & 4.39 & - & $3 / 3$ & & \\
\hline II-17 & 24.8 & 53 & $\mathbf{M}$ & 0.83 & 5.68 & 0.39 & 0.48 & 0.01 & 4.06 & 1.22 & 7.59 & - & $3 / 2$ & & \\
\hline II- 18 & 24.3 & 48 & $\mathbf{F}$ & 2.96 & 8.69 & 2.86 & 1.40 & 1.28 & 3.15 & 1.40 & 28.68 & + & $3 / 3 \mathrm{~L}$ & & III \\
\hline II-19 & 28.1 & 49 & $\mathbf{M}$ & 2.28 & 6.08 & 1.03 & 0.48 & 0.06 & 4.34 & 0.65 & 4.73 & - & $3 / 3$ & & \\
\hline II-20 & 24.7 & 46 & $\mathbf{F}$ & 2.18 & 8.81 & 1.75 & 1.39 & 1.27 & 3.73 & 2.06 & 26.06 & + & $3 / 3 \mathrm{~L}$ & & III \\
\hline II-21 & 24.0 & 45 & $\mathbf{M}$ & 1.26 & 6.72 & 0.54 & 0.66 & 0.29 & 4.17 & 1.72 & 4.62 & - & $4 / 3$ & & II \\
\hline II-22 & 20.0 & 44 & $\mathbf{F}$ & 0.98 & 6.60 & 0.44 & 0.50 & 0.05 & 4.07 & 2.04 & 3.42 & - & $4 / 3$ & & \\
\hline II-23 & 25.7 & 42 & $\mathbf{M}$ & 2.05 & 9.00 & 0.95 & 0.60 & 0.27 & 6.11 & 1.67 & 6.31 & - & $4 / 3$ & & II \\
\hline II-24 & 25.9 & 41 & $\mathbf{M}$ & 4.57 & 14.68 & 6.29 & 1.97 & 2.70 & 4.19 & 1.50 & 44.83 & + & $3 / 3 \mathrm{~L}$ & $\mathbf{X}$ & III, Med \\
\hline II-25 & 20.3 & 38 & $\mathbf{F}$ & 0.69 & 4.28 & 0.14 & & & & 1.38 & 2.94 & - & $4 / 3$ & & \\
\hline II-26 & 26.9 & 39 & $\mathbf{M}$ & 1.87 & 7.74 & 0.87 & 0.58 & 0.22 & 5.27 & 1.38 & 5.62 & - & $4 / 3$ & & II \\
\hline II-27 & 27.5 & 36 & $\mathbf{M}$ & 1.41 & 7.69 & 0.79 & 1.04 & 0.67 & 4.90 & 1.33 & 5.60 & - & $4 / 3$ & & II \\
\hline II-28 & 22.4 & 34 & $\mathbf{M}$ & 0.47 & 5.05 & 0.11 & 0.32 & 0.04 & 3.23 & 1.67 & 2.58 & - & $4 / 3$ & & \\
\hline II-29 & 23.6 & 33 & $\mathrm{~F}$ & 0.67 & 6.62 & 0.18 & 0.51 & 0.16 & 4.44 & 1.84 & 6.05 & - & $4 / 3$ & & \\
\hline II-30 & 19.8 & 29 & $F$ & 2.83 & 8.80 & 2.52 & 1.27 & 1.06 & 3.17 & 2.05 & 27.51 & + & $3 / 3 \mathrm{~L}$ & & III \\
\hline III-1 & 19.6 & 27 & $\mathrm{~F}$ & 0.70 & 4.65 & 0.10 & 0.26 & 0.08 & 2.39 & 2.08 & 5.95 & - & $3 / 3$ & & \\
\hline III-2 & 17.8 & 24 & $\mathbf{F}$ & 1.45 & 4.81 & 0.37 & 0.42 & 0.24 & 2.53 & 1.67 & 5.23 & - & $3 / 3$ & & \\
\hline III-3 & 20.0 & 23 & $\mathrm{~F}$ & 1.25 & 4.43 & 0.72 & 0.87 & 0.37 & 1.97 & 1.37 & 14.30 & + & $3 / 3 \mathrm{~L}$ & & III \\
\hline III-4 & 19.6 & 26 & $F$ & 1.14 & 5.46 & 0.44 & 0.87 & 0.55 & 2.59 & 1.88 & 12.74 & + & $4 / 3 \mathrm{~L}$ & & III \\
\hline III-5 & 25.0 & 25 & $\mathbf{M}$ & 1.37 & 5.17 & 0.61 & 0.83 & 0.53 & 2.85 & 1.18 & 15.82 & + & $4 / 3 \mathrm{~L}$ & & III \\
\hline III-6 & 19.6 & 23 & $\mathbf{M}$ & 0.95 & 3.94 & 0.45 & 1.09 & 0.59 & 1.72 & 1.18 & 11.11 & + & $3 / 3 \mathrm{~L}$ & & III \\
\hline III-7 & 19.6 & 20 & $F$ & 0.40 & 3.67 & 0.06 & 0.45 & 0.12 & 1.77 & 1.72 & 4.76 & - & $3 / 3$ & & \\
\hline III-8 & 19.6 & 18 & $\mathbf{M}$ & 0.66 & 3.64 & 0.18 & 0.53 & 0.17 & 2.00 & 1.29 & 2.41 & - & $4 / 3$ & & \\
\hline III-9 & 19.0 & 17 & $\mathbf{M}$ & 1.31 & 4.51 & 0.70 & 1.23 & 0.91 & 1.87 & 1.03 & 12.10 & + & $4 / 3 \mathrm{~L}$ & & III \\
\hline III-10 & 22.3 & 21 & $\mathrm{~F}$ & 1.09 & 4.02 & 0.25 & 0.45 & 0.24 & 1.76 & 1.77 & 2.20 & - & $4 / 3$ & & \\
\hline III-1 1 & 19.4 & 20 & $\mathbf{M}$ & 0.71 & 3.86 & 0.18 & 0.51 & 0.18 & 2.17 & 1.33 & 2.18 & - & $3 / 3$ & & \\
\hline III-12 & 17.3 & 15 & $\mathbf{M}$ & 0.66 & 4.70 & 0.11 & 0.74 & 0.38 & 2.44 & 1.77 & 2.50 & - & $3 / 3$ & & \\
\hline III- 13 & 18.7 & 11 & $\mathbf{M}$ & 2.30 & 6.29 & 1.17 & 1.08 & 1.31 & 2.70 & 1.11 & 20.90 & + & $3 / 3 \mathrm{~L}$ & & III \\
\hline III-14 & 16.6 & 9 & $\mathbf{M}$ & 1.66 & 5.34 & 1.04 & 1.30 & 1.12 & 2.21 & 0.97 & 14.72 & + & $3 / 3 \mathrm{~L}$ & & III \\
\hline III- 15 & 15.6 & 7 & $\mathbf{M}$ & 2.62 & 5.27 & 1.41 & 0.75 & 0.56 & 2.03 & 1.27 & 15.90 & + & $3 / 3 \mathrm{~L}$ & & III \\
\hline III-16 & 15.7 & 5 & $\mathbf{M}$ & 0.70 & 3.98 & & 0.61 & 0.43 & 3.55 & & 4.30 & - & $3 / 3$ & & \\
\hline III- 17 & 21.7 & 25 & $\mathbf{M}$ & 0.90 & 4.89 & 0.32 & 0.46 & 0.09 & 2.98 & 1.50 & 5.76 & - & $3 / 2$ & & \\
\hline III-18 & 22.0 & 23 & $\mathrm{~F}$ & 2.56 & 7.16 & 2.39 & 1.34 & 1.04 & 2.09 & 1.64 & 28.11 & + & $2 / 3 \mathrm{~L}$ & & III \\
\hline III-19 & 23.3 & 19 & $\mathbf{M}$ & 2.56 & 5.75 & 2.29 & 0.85 & & 2.66 & 0.92 & 18.17 & + & $3 / 3 \mathrm{~L}$ & & III \\
\hline III-20 & 21.5 & 23 & $\mathbf{M}$ & 1.22 & 4.71 & 0.46 & 0.45 & 0.09 & 3.13 & 1.03 & 3.60 & - & $3 / 3$ & & \\
\hline III-21 & 22.6 & 20 & $\mathbf{M}$ & 3.89 & 9.96 & 4.17 & 0.90 & & 5.24 & 1.21 & 26.88 & + & $3 / 3 \mathrm{~L}$ & & III \\
\hline III-22 & 20.4 & 20 & $\mathbf{M}$ & 0.86 & 4.32 & 0.21 & 0.26 & 0.01 & 2.71 & 1.39 & 4.18 & - & $3 / 3$ & & \\
\hline III-23 & & 14 & $\mathbf{M}$ & 0.95 & 4.03 & 0.19 & & & & 1.34 & 3.50 & - & $4 / 3$ & & \\
\hline III-24 & & 12 & $\mathbf{M}$ & 0.98 & 4.89 & 0.29 & & & & 1.69 & 5.12 & - & $3 / 3$ & & \\
\hline
\end{tabular}

Clinical variables of the 128 family members of the extended Dutch ApoE3-Leiden pedigree. The subject numbering corresponds with the one presented in the pedigree (Fig. 5). Subject number, BMI, age, sex, total plasma triglycerides, total plasma cholesterol, VLDL-cholesterol, ratio (VLDL + IDL)-cholesterol/total plasma triglycerides, IDL-cholesterol, LDL-cholesterol, HDL-cholesterol, plasma apoE concentration, presence $(+)$ or absence $(-)$ of $\beta$-VLDL evaluated by agarose electrophoresis ( $\beta$-VLDL), apoE phenotype, clinical symptoms of the individuals observed at their first visit to lipid clinic, and remarks are shown. Abbreviations used under clinical symptoms are: $X$, xanthomas including palmar streaks, tendinous xanthomas, and tuberous xanthomas; C, coronary vascular disease. Abbreviations used under remarks are: II, III, IV, subject was classified as having either type IIa or IIb, type III, or type IV hyperlipoproteinemia, based on the observed lipid and lipoprotein levels, agarose electrophoresis, and other clinical symptoms; Med, subject using lipid lowering drugs. * $3 \mathrm{~L}$, apoE3-Leiden.

\section{Acknowledgments}

The authors thank Dr. Mary-Yvonne Rosseneu and Christine Labeur (Department of Clinical Chemistry, Algemeen Ziekenhuis St. Jan, Brugge, Belgium) for providing us with their facilities for quantifying the plasma apoE levels; Inge de Bruÿn, Kees Braun, and Elly de Wit for their excellent technical assistance; and Lenie van Mourik for her help in collecting family data and obtaining plasma samples. This work was supported in part by the Praeventie Fonds (grant no. 28-1716 to Dr. de Knijff) and the Netherlands Heart Foundation (grant no. 88.086 to Dr. van den Maagdenberg). Dr. Stalenhoef is a clinical investigator of the Netherlands Heart Foundation. 


\section{References}

1. Mahley, R. W., and S. C. Rall. 1989. Type III hyperlipoproteinemia (dysbetalipoproteinemia): the role of apolipoprotein $\mathrm{E}$ in normal and abnormal lipoprotein metabolism. In The Metabolic Basis of Inherited Disease. 6th edition. C. R. Scriver, A. L. Beaudet, W. S. Sly, and D. Valle, editors. McGraw-Hill Book Co., Inc., New York. 1195-1213

2. Fainaru, M., R. W. Mahley, R. L. Hamilton, and T. L. Innerarity. 1982. Structural and metabolic heterogeneity of $\beta$-very low density lipoproteins from cholesterol-fed dogs and from humans with type III hyperlipoproteinemia. $J$. Lipid Res. 23:702-714.

3. Kane, J. P., G. C. Chen, R. L. Hamilton, D. A. Hardman, M. J. Malloy, and R. J. Havel. 1983. Remnants of lipoproteins of intestinal and hepatic origin in familial dysbetalipoproteinemia. Arteriosclerosis. 3:47-56.

4. Havel, R. J., and J. P. Kane. 1973. Primary dysbetalipoproteinemia: predominance of a specific apoprotein species in triglyceride-rich lipoproteins. Proc Natl. Acad. Sci. USA. 70:2015-2019.

5. Havel, R. J., Y.-C. Chao, E. E. Windler, L. Kotite, and L. S. S. Guo. 1980. Isoprotein specificity in the hepatic uptake of apolipoprotein $\mathrm{E}$ and the pathogenesis of familial dysbetalipoproteinemia. Proc. Natl. Acad. Sci. USA. 77:4349-4353.

6. Sherril, B. C., T. L. Innerarity, and R. W. Mahley. 1980. Rapid hepatic clearance of the canine lipoproteins containing only the $\mathrm{E}$ apoprotein by a high affinity receptor. J. Biol. Chem. 225:1804-1807.

7. Mahley, R. W., and B. Angelin. 1984. Type III hyperlipoproteinemia: recent insights into the genetic defect of familial dysbetalipoproteinemia. $A d v$. Intern. Med. 29:385-411.

8. Stalenhoef, A. F. H., M. J. Malloy, J. P. Kane, and R. J. Havel. 1986. Metabolism of apolipoproteins B-48 and B-100 of triglyceride-rich lipoproteins in patients with familial dysbetalipoproteinemia. J. Clin. Invest. 78:722-728.

9. Zannis, V. I., and J. L. Breslow. 1981. Human very low density lipoprotein apoprotein $\mathrm{E}$ isoprotein polymorphism is explained by genetic variation and posttranslational modification. Biochemistry. 20:1033-1041.

10. Weisgraber, K. H., T. L. Innerarity, and R. W. Mahley. 1982. Abnormal lipoprotein receptor-binding activity of the human $\mathrm{E}$ apoprotein due to cysteinearginine interchange at a single site. J. Biol. Chem. 257:2518-2521.

11. Utermann, G. 1982. Apolipoprotein E (role in lipoprotein metabolism and pathophysiology of hyperlipoproteinemia type III. Ric. Clin. Lab. 12:23-33.

12. Utermann, G. 1985. Genetic polymorphism of apolipoprotein E: impact on plasma lipoprotein metabolism. In Diabetes, Obesity and Hyperlipidemias III. G. Crepaldi, A. Tiengo, and G. Baggio, editors. Excerpta Medica, Amsterdam. $1-28$.

13. Havel, R. J., L. Kotite, J. P. Kane, P. Tun, and T. Bersot. 1983. Atypical familial dysbetalipoproteinemia associated with apolipoprotein phenotype E3/3. J. Clin. Invest. 72:379-387.

14. Rall, S. C., Jr., Y. M. Newhouse, H. R. G. Clarke, K. H. Weisgraber, B. J. McCarthy, R. W. Mahley, and T. Bersot. 1989. Type III hyperlipoproteinemi associated with apolipoprotein E phenotype E3/3: structure and genetics of an apolipoprotein E3 variant. J. Clin. Invest. 83:1095-1101.

15. Rall, S. C., Jr., K. H. Weisgraber, T. L. Innerarity, T. P. Bersot, R. W. Mahley, and C. B. Blum. 1983. Identification of a new structural variant of human apolipoprotein E, E2(Lys ${ }_{146} \rightarrow$ Gln), in a type III hyperlipoproteinemic subject with the E3/2 phenotype. J. Clin. Invest. 72:1288-1297.

16. Smit, M., P. de Knijff, R. R. Frants, E. C. Klasen, and L. M. Havekes 1987. Familial dysbetalipoproteinemic subjects with the E3/E2 phenotype exhibit an E2 isoform with only one cysteine residue. Clin. Genet. 32:335-341.

17. Smit, M., P. de Knijff, E. van der Kooij-Meijs, C. Groenendijk, A. M. J. M. van den Maagdenberg, J. A. Gevers Leuven, A. F. H. Stalenhoef, P. M. J. Stuyt, R. R. Frants, and L. M. Havekes. 1990. Genetic heterogeneity in familial dysbetalipoproteinemia: the E2(Lys146 $\rightarrow$ Gln) variant results in a dominant mode of inheritance. J. Lipid Res. 31:45-53.

18. Mann, W. A., R. E. Gregg R. Ronan, F. Thomas, L. A. Zech, and H. B. Brewer, Jr. 1988. Apolipoprotein E1-Harrisburg: point mutation resulting in dominant expression of type III hyperlipoproteinemia. 1988. Arteriosclerosis. 8:612a. (Abstr.)

19. Mann, W. A., R. E. Gregg D. L. Sprecher, and H. B. Brewer, Jr. 1989. Apolipoprotein E1-Harrisburg: a new variant of apolipoprotein E dominantly associated with type III hyperlipoproteinemia. Biochim. Biophys. Acta. 1005:239-244.

20. Havekes, L. M., J. A. Gevers Leuven, E. van Corven, E. de Wit, and J. J. Emeis. 1984. Functionally inactive apolipoprotein E3 in a type III hyperlipoproteinaemic patient. Eur. J. Clin. Invest. 14:7-11.

21. Havekes, L., E. de Wit, J. Gevers Leuven, E. Klasen, G. Utermann, W. Weber, and U. Beisiegel. 1986. Apolipoprotein E3-Leiden. A new variant of human apolipoprotein $\mathrm{E}$ associated with familial type III hyperlipoproteinemia. Hum. Genet. 73:157-163.
22. Paik, Y.-K., D. J. Chang, C. A. Reardon, G. E. Davies, R. W. Mahley, and J. M. Taylor. 1985. Nucleotide sequence and structure of the human apolipoprotein E gene. Proc. Natl. Acad. Sci. USA. 82:3445-3449.

23. van den Maagdenberg, A. M. J. M., P. de Knijff, A. F. H. Stalenhoef, J. A. Gevers Leuven, L. M. Havekes, and R. R. Frants. 1989. Apolipoprotein E*3-Leiden allele results from a partial gene duplication in exon 4. Biochem. Biophys. Res. Commun. 165:851-857.

24. Wardell, M. R., K. H. Weisgraber, L. M. Havekes, and S. C. Rall, Jr. 1989. Apolipoprotein E3-Leiden contains a seven-amino acid insertion that is a tandem repeat of residues 121-127. J. Biol. Chem. 264:21205-21210.

25. Lopez-Virella, M. F., P. Stone, S. Ellis, and J. A. Colwell. 1977. Cholesterol determination in high-density lipoproteins separated by three different methods. Clin. Chem. 23:882-884.

26. Demacker, P. N. M., H. E. Vos-Janssen, A. van't Laar, and A. P. Jansen. 1978. A descriptive study of the different electrophorotic patterns in agarose of human serum very low density lipoproteins. Clin. Chem. 24:1439-1444.

27. Bury, J., R. Vercaemst, M. Rosseneu, and F. Belpaire. 1986. Apolipoprotein $\mathrm{E}$ quantified by enzyme-linked immunosorbent assay. Clin. Chem. 32:265270 .

28. Havekes, L. M., P. de Knijff, U. Beisiegel, J. Havinga, M. Smit, and E. Klasen. 1987. A rapid micro-method for apolipoprotein $\mathrm{E}$ phenotyping directly in serum. J. Lipid Res. 28:445-463.

29. Redgrave, T. G., D. C. K. Roberts, and C. E. West. 1975. Separation of plasma lipoproteins by density gradient centrifugation. Anal. Biochem. 65:42-49.

30. Miller, S. A., D. D. Dykes, and H. F. Polesky. 1988. A simple salting out procedure for extracting DNA from human nucleated cells. Nucleic Acids Res. 16:1215.

31. Hixson, J. E., and D. T. Vernier. 1990. Restriction isotyping of human apolipoprotein E by gene amplification and cleavage with HhaI. J. Lipid Res. 31:545-548.

32. Stalenhoef, A. F. H., P. N. M. Demacker, P. de Knijff, and L. M. Havekes 1989. Apolipoprotein E3-Nijmegen, resulting in dominant expression of familia dysbetalipoproteinemia (FD). Arteriosclerosis. 9:764a. (Abstr.)

33. Weintraub, M. S., S. Eisenberg, and J. L. Breslow. 1987. Dietary fat clearance in normal subjects is regulated by genetic variation in apolipoprotein $\mathrm{E}$. $J$. Clin. Invest. 80:1571-1577.

34. Rall, S. C., Jr., K. H. Weisgraber, T. L. Innerarity, and R. W. Mahley. 1982. Structural basis for receptor binding heterogeneity of apolipoprotein E from type III hyperlipoproteinemic subjects. Proc. Natl. Acad. Sci. USA. 79:4696-4700.

35. Emi, M., L. L. Wu, M. A. Robertson, R. L. Myers, R. A. Hegele, R. R Williams, R. White, and J.-M. Lalouel. 1988. Genotyping and sequence analysis of apolipoprotein E isoforms. Genomics. 3:373-379.

36. Wardell, M. R., S. O. Brennan, E. D. Janus, R. Fraser, and R. W. Carrel. 1987. Apolipoprotein E2-Christchurch (136Arg $\rightarrow$ Ser): new variant of human apolipoprotein $\mathrm{E}$ in a patient with type III hyperlipoproteinemia. J. Clin. Invest. 80:483-490.

37. Innerarity, T. L., E. J. Friedlander, S. C. Rall, Jr., K. H. Weisgraber, and R. W. Mahley. 1983. The receptor-binding domain of human apolipoprotein E: binding of apolipoprotein E fragments. J. Biol. Chem. 258:12341-12347.

38. Innerarity, T. L., K. H. Weisgraber, K. S. Arnold, S. C. Rall, Jr., and R. W. Mahley. 1984. Normalization of receptor binding of apolipoprotein E2: evidence for modulation of the binding site conformation. J. Biol. Chem. 259:7261-7267.

39. Lalazar, A., K. H. Weisgraber, S. C. Rall, Jr., H. Giladi, T. L. Innerarity, A. Z. Levanon, J. K. Boyles, B. Amit, M. Gorecki, R. W. Mahley, et al. 1988. Site-specific mutagenesis of human apolipoprotein E: receptor binding activity of variations with single amino acid substitutions. J. Biol. Chem. 263:3542-3545.

40. Innerarity, T. L., D. Y. Hui, T. P. Bersot, and R. W. Mahley. 1986. Type III hyperlipoproteinemia: a focus on lipoprotein receptor-apolipoprotein E2 interactions. In Lipoprotein Deficiency Syndromes. A. Angelin, and J. Frohlich, editors. Plenum Publishing Corp., New York. 273-288.

41. Mahley, R. W., T. L. Innerarity, S. C. Rall, Jr., K. H. Weisgraber, and J. M. Taylor. 1990. Apolipoprotein E: genetic variants provide insights into its structure and function. Curr. Opin. Lipidol. 1:87-95.

42. Mahley, R. W. 1988. Apolipoprotein E: cholesterol transport protein with expanding role in cell biology. Science (Wash. DC). 240:622-630.

43. Mahley, R. W., K. H. Weisgraber, M. M. Hussain, B. Greenman, M. Fisher, T. Vogel, and M. Gorecki. 1989. Intravenous infusion of apolipoprotein E accelerates clearance of plasma lipoproteins in rabbits. J. Clin. Invest. 83:21252130.

44. Gregg, R. E., L. A. Zech, E. J. Schaefer, D. Sterk, D. Wilson, and H. B. Brewer, Jr. 1986. Abnormal in vivo metabolism of apolipoprotein E4 in humans. J. Clin. Invest. 78:815-821.

45. Weisgraber, K. H. 1990. Apolipoprotein E distribution among human plasma lipoproteins: role of the cysteine-arginine interchange at residue $112 . J$. Lipid Res. 31:1503-1511. 